\title{
اتجاهات البحث العلمي في الصحافة المتخصصة
}

مجلة الباحث الإعلامي انموذجا - دراسة مسحية -

أ.م.د. شكرية كوكز السراج

كليَة الإعلام - جامعة بغداد

مستخلص

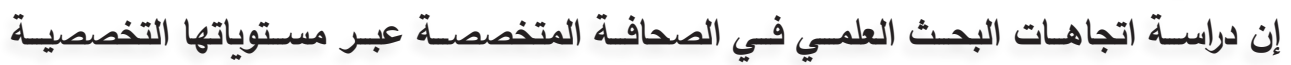

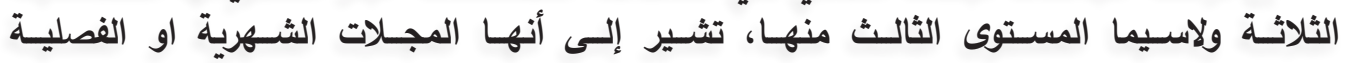

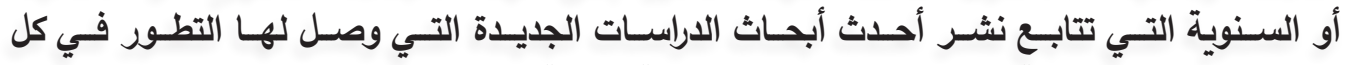

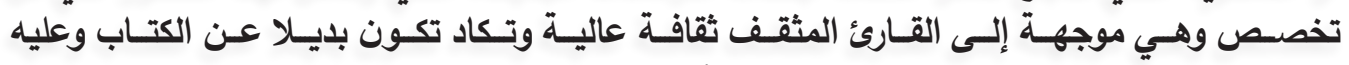

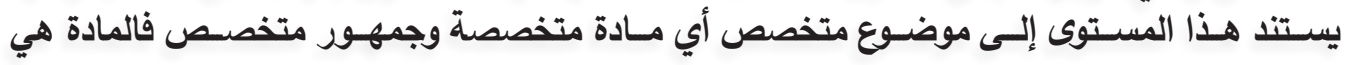

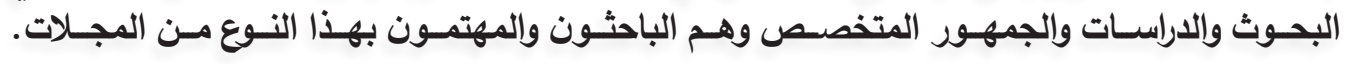

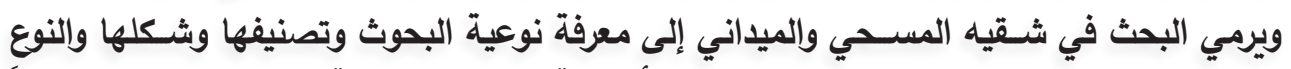

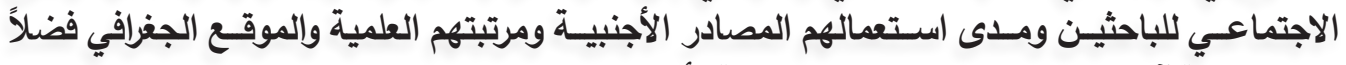

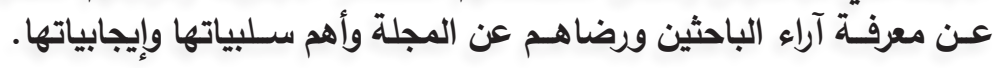
وقد توصلت الباحثة إلى طائفة من النتائج منها :

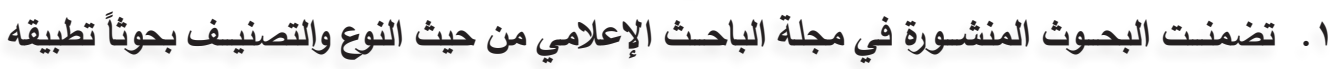

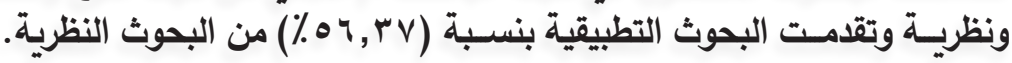

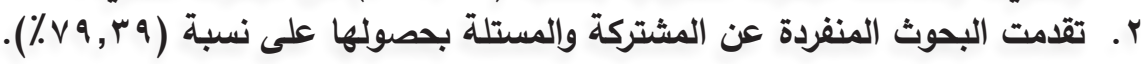

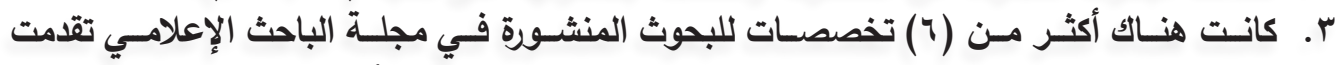

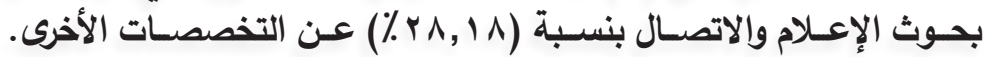

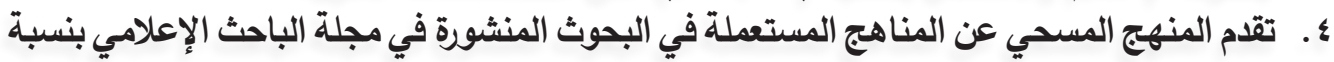

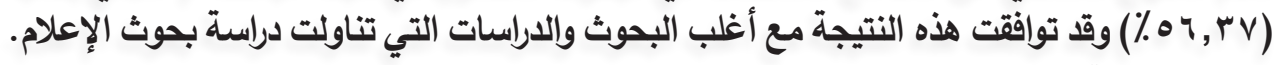

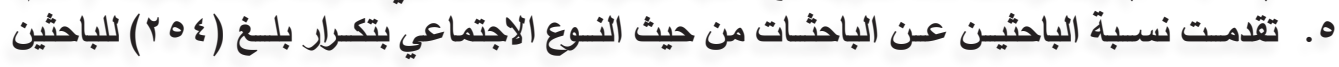

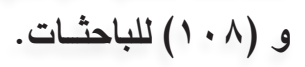

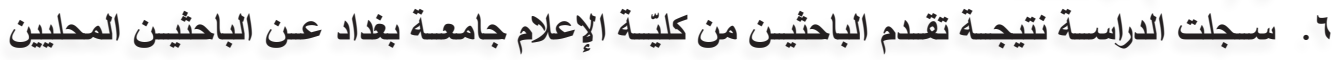

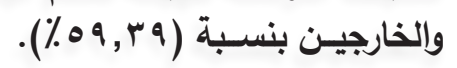

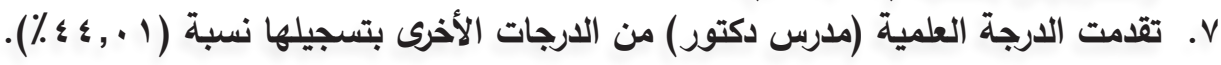

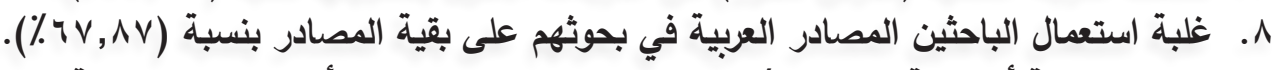

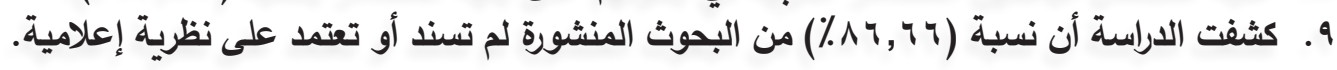

drshuqriah@comc.uobaghdad.edu.iq

\begin{tabular}{c|c} 
& مجلة الباحث الإعلامي \\
\hline$q$ & ( العدد (rq )
\end{tabular}




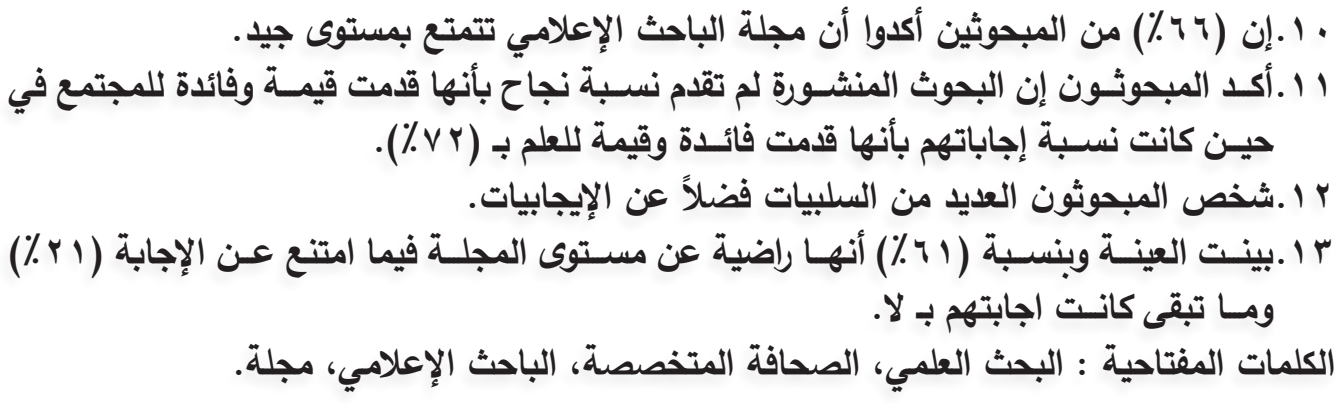

Tendencies of Scientific Research in the Specialized Journalism the Media Researcher Magazine A survey study

Prof. Assist. Dr. Shukria Kawkaz Al-Saraj

College of Media - Baghdad University - Shukriakawkaz@yahoo.com

\section{Abstract}

The study of the tendencies of scientific research in the specialized journalism through the three specialized levels, specifically the third level. It is referred to be a monthly, quarterly or annual magazine that follows the publication of the researches for new studies which have come to in every specialization. it is directed to the highly educated and is almost an alternative book. Thus, the subject is specialized and the audience is specialized.

The study aims in both its survey and field section at knowing the type of researches and their classification and the form, gender and the use of foreign sources and their scientific tank and the geographical position in addition to knowing the opinions of researchers and their satisfaction about the magazine and the most important advantages and disadvantages.

The researcher comes up to the following findings:

The published researches in the Media Researcher magazine includes applied and theoretical studies in the coordination researches in $56.37 \%$ of the theoritcal researches.

The individual researches exceed the joined researches in obtaining $79.39 \%$.

There are more than 6 specializations of the researches published in the magazine. The researchesaboutmedia and communication come firstin $28.18 \%$.

The subject affirmed that the published researches did not give success rat while the percentage of their answers whether they are useful and benifitable was $82 \%$.

The subject diagnosed many disadvantages.

The sample showed that $621 \%$ that they are satisfied and $21 \%$ were not.

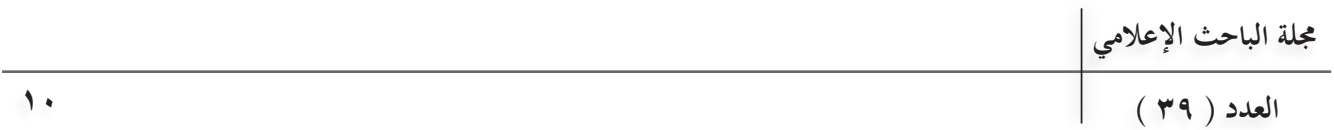




\section{مقدمة}

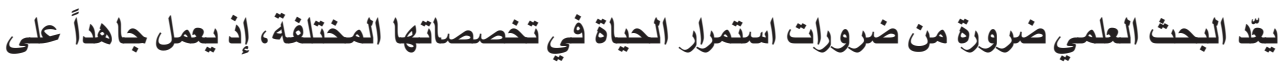

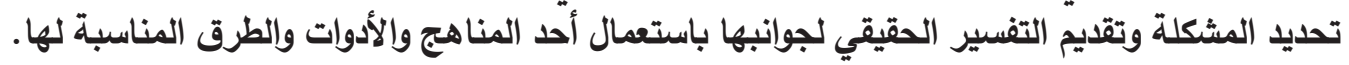

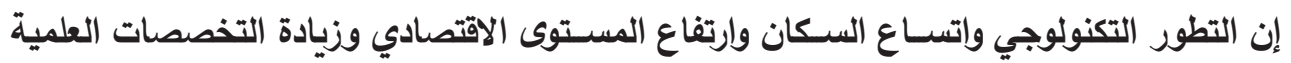

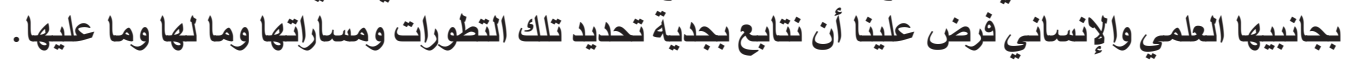

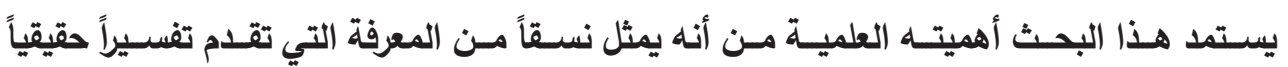

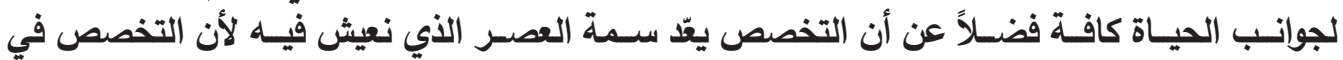

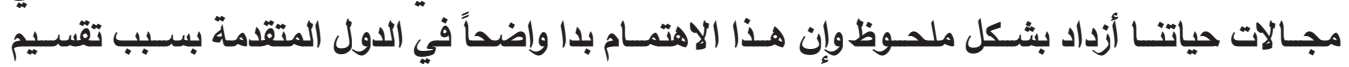

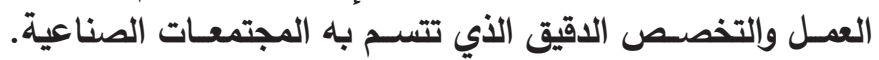

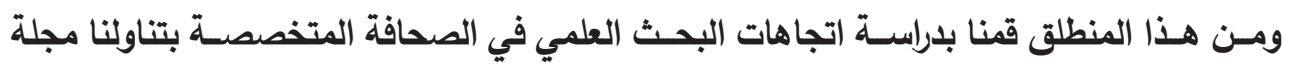

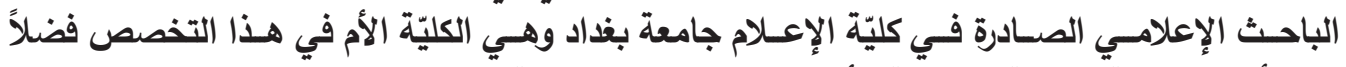

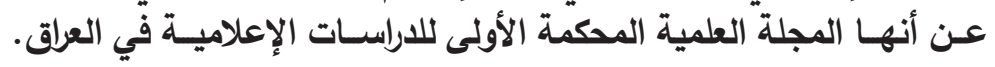

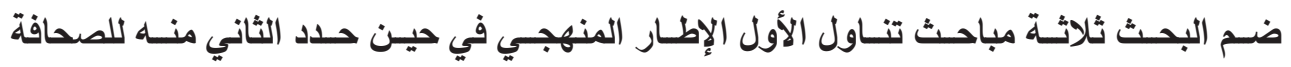

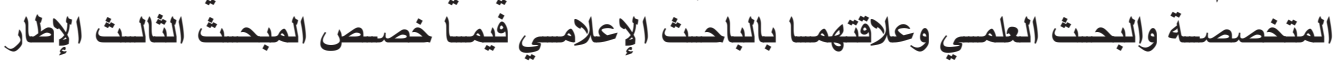

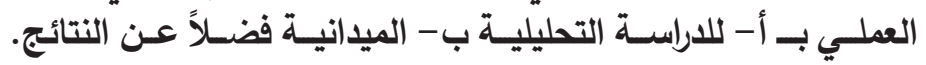
الإطار المنهجي

\section{أولا : أهمية البحث العلمي والحاجة إليه}

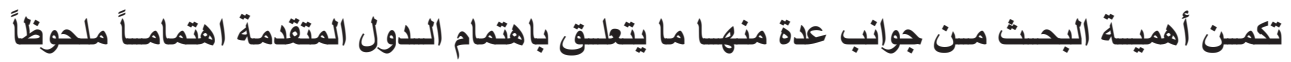

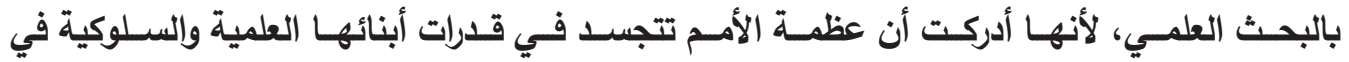

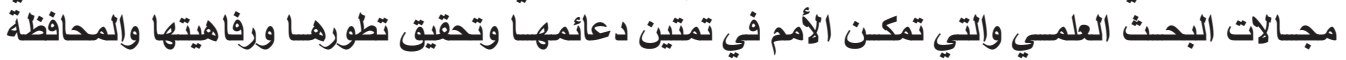

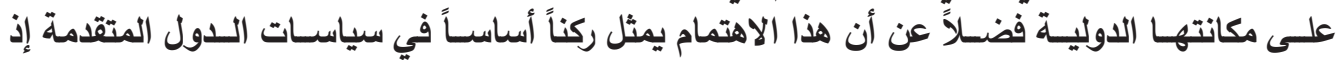

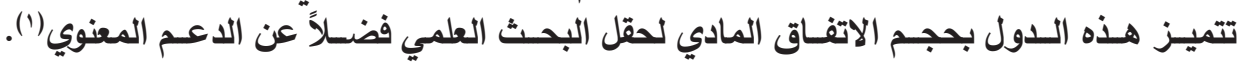

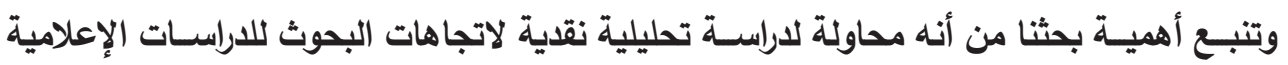

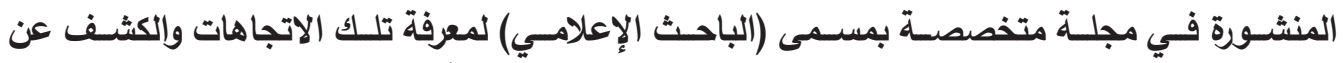

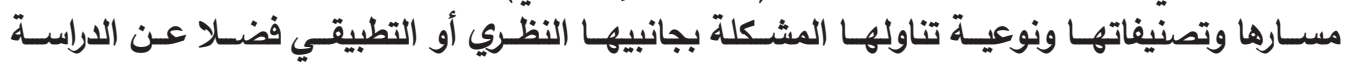

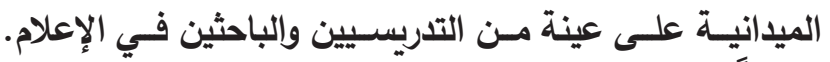
ثانياً:مشكلة البحث عينة

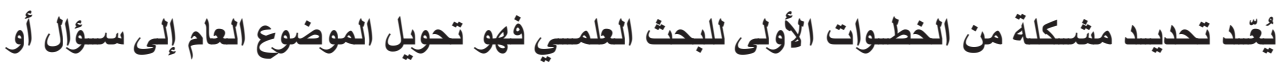

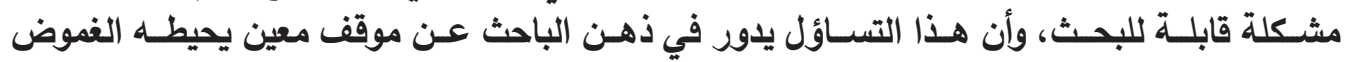

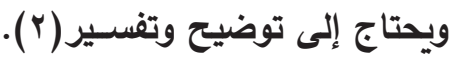


ويـرى كثيـر مـن العلماء إن تحديد المشـكلة من أجل دراسـتها أصعب بكثير مـن إيجاد الحلول لها

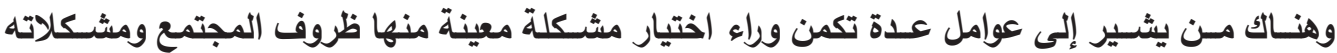

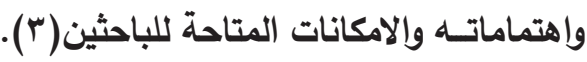

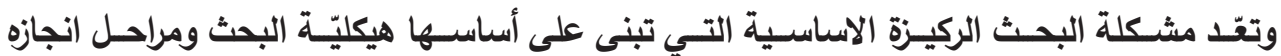

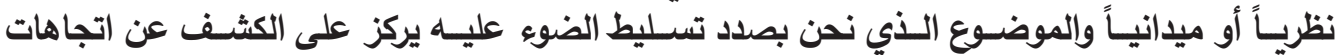

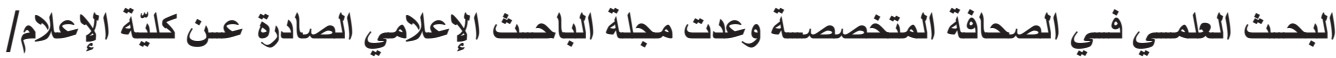

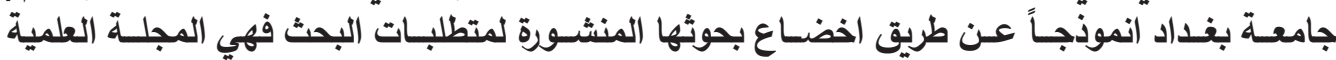

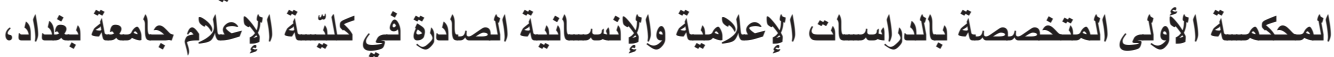

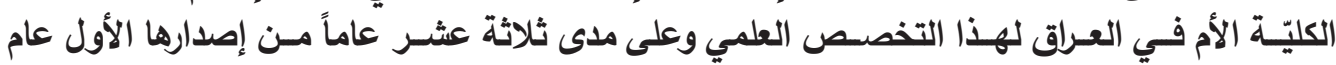

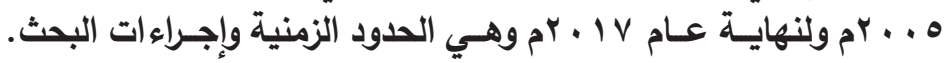

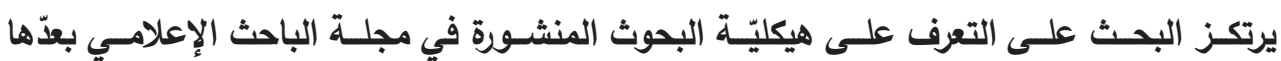

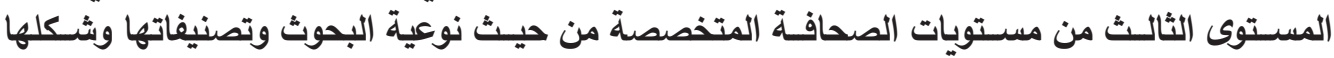

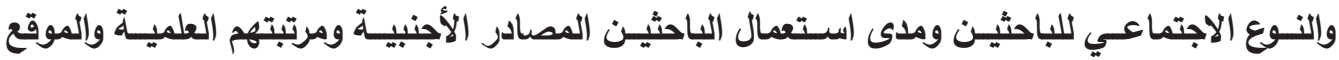

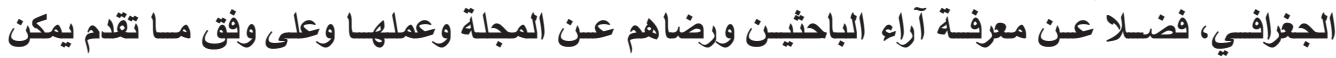
تلخيص مشـكلة البحـث في الإجابـة عن التســاؤلات الآتية :

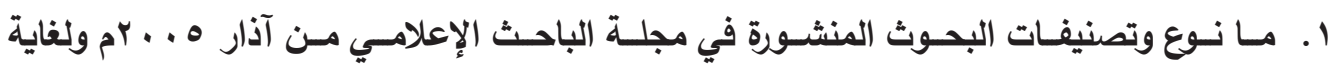
Pr. IV/T/r/

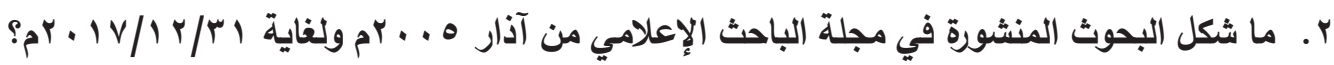

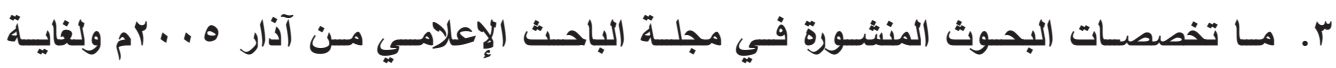

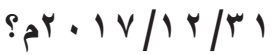

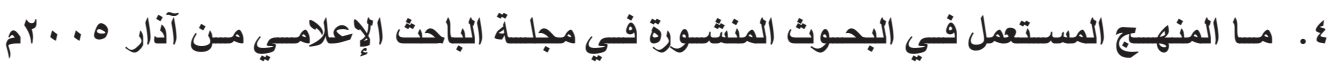

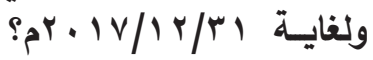

هـ . مـا نسـبة توزيع النـوع الاجتماعي للباحثيـن (ذكر -إنثى) للباحثين المشـاركين فـي مجلة الباحث

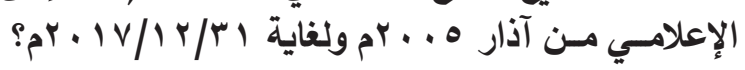

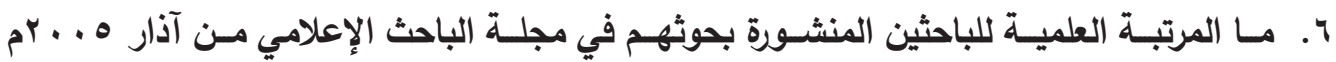

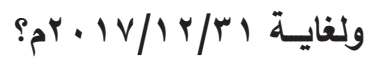

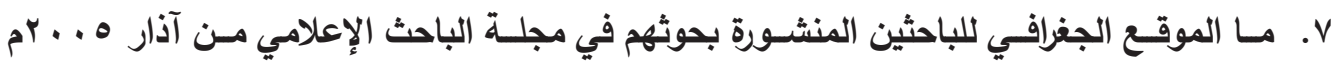

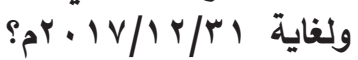
^. ما نسـبة اســعمال الباحثين المصادر الأجنبية في بحوثهم المنثـورة في مجلة الباحث الإعلامي

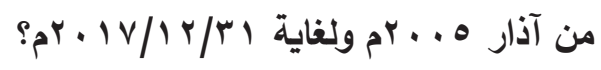

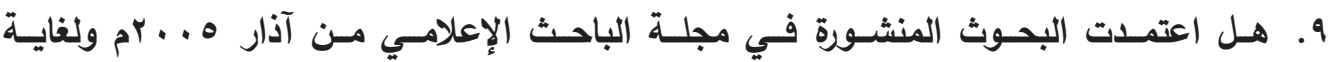

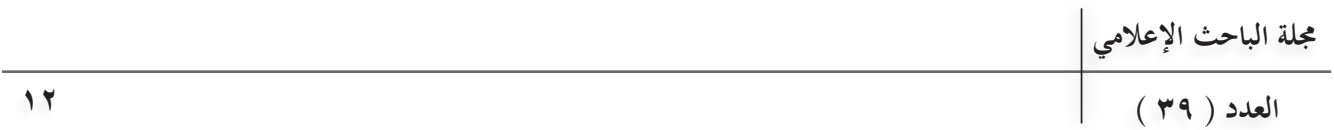




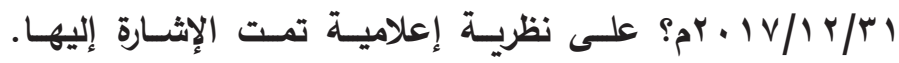

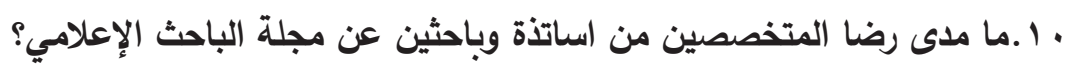

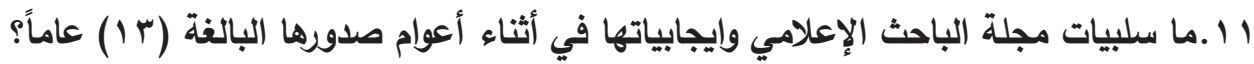

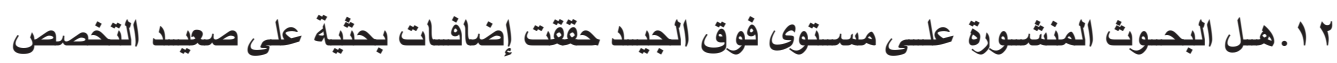

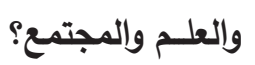
ثالثاً : أهداف البحث ولمث يرمي البحث الحالي إلى :

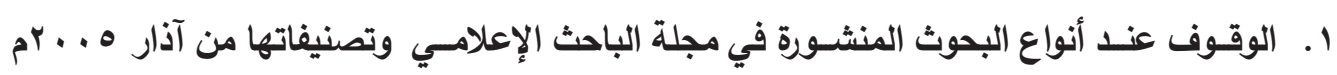

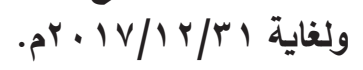

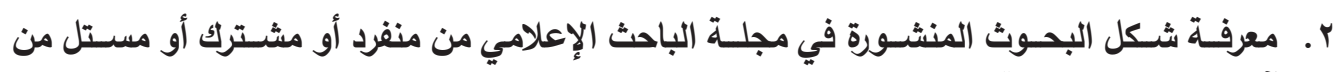

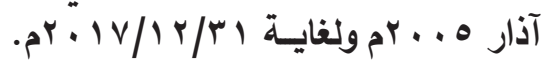

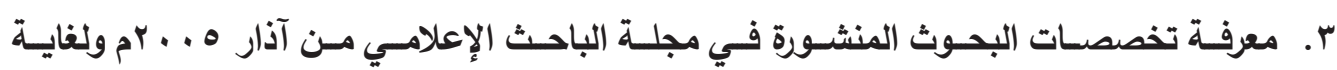

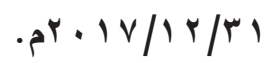

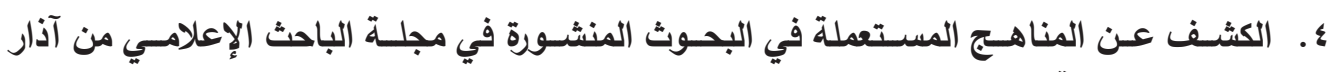

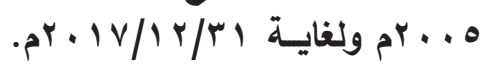

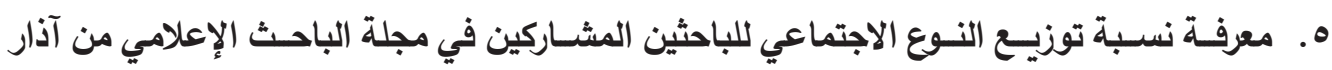

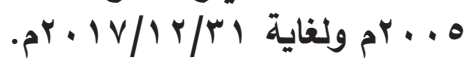
צ. بيان المرتبة العلمية للباحثين المنشورة بحوثهم في مجلة الباحث الإعلامي وللمدة المشار إليها أعلاه. V. . . عديد الموقع الجغرافي للباحثين المنشورة بحوثهم في مجلة الباحث الإعلامي.

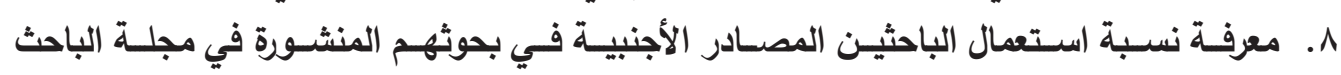

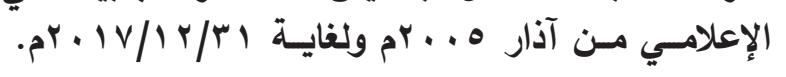

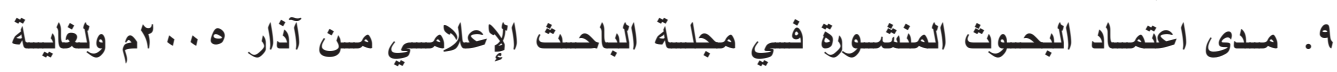
ا

• 1 .معرفة مدى رضا من قبل المتخصصين من اساتذة وباحثين عن مجلة الباحث الإعلامي.

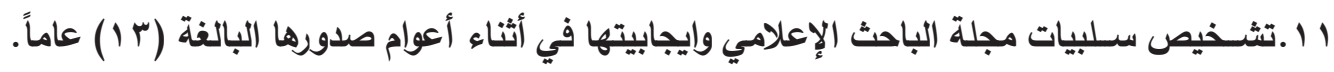

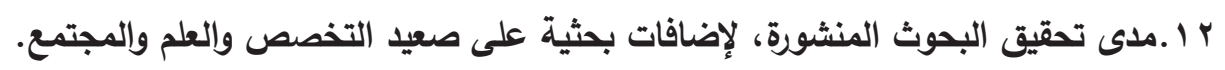

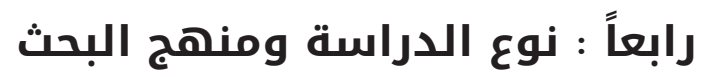

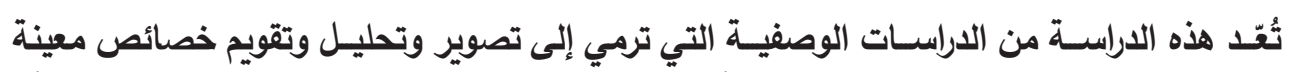

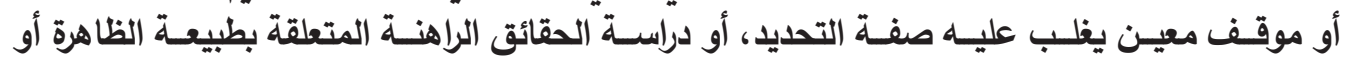

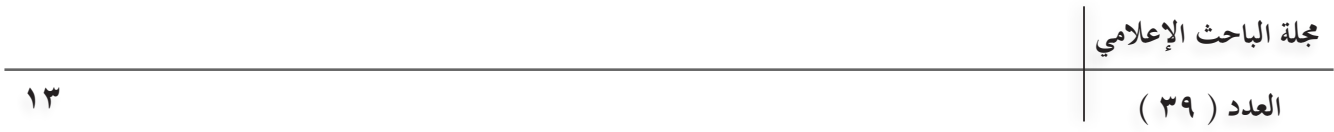




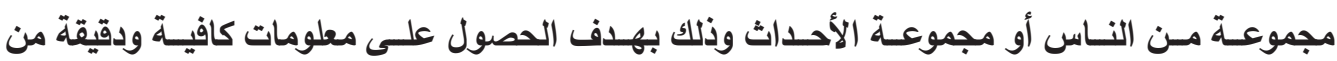
دون الاخــول في أسـبابها أو التحكم فيها (؛ ؛ ).

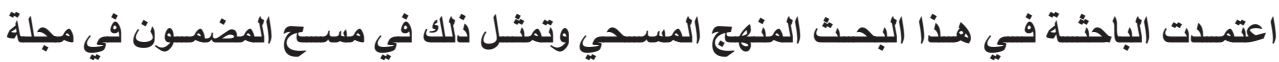

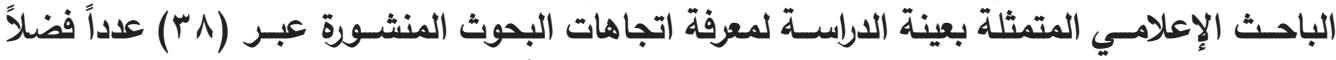

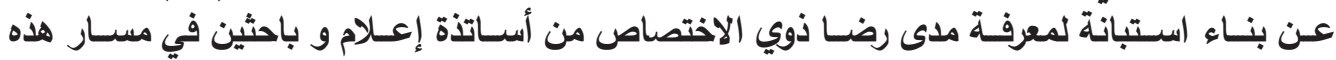

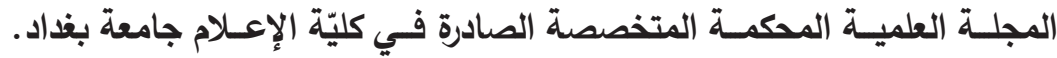

\section{خامساً : مجالات البحث}

وتقسم على ثلاثة مجالات :

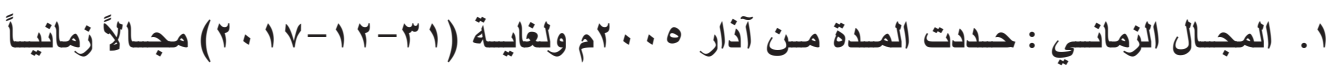

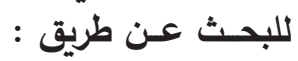

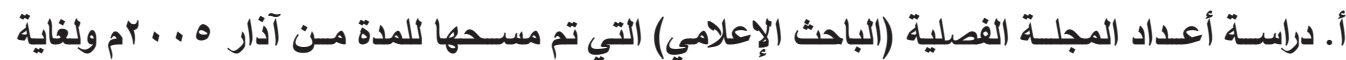

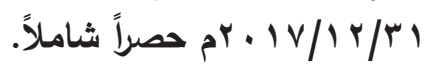

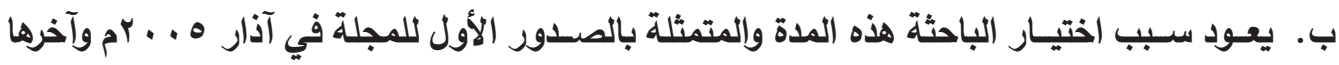

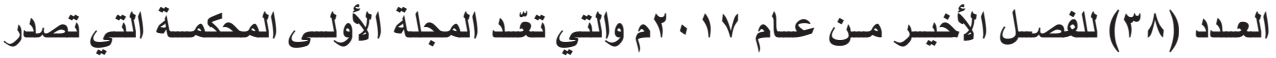

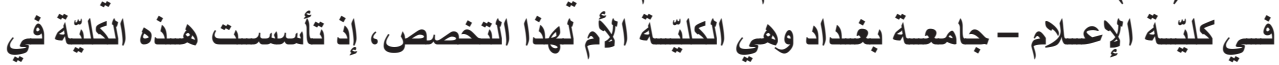

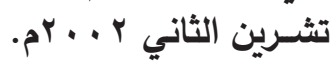

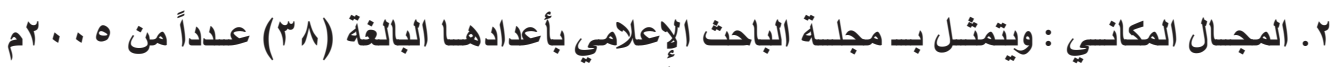

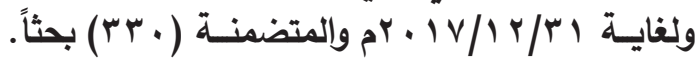

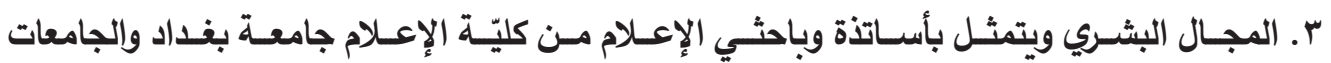

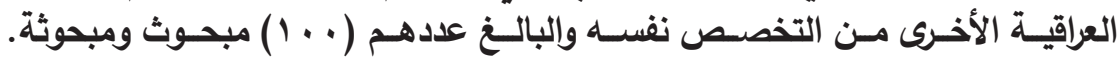
سادساً : عينة البحث وتشمل العينة :

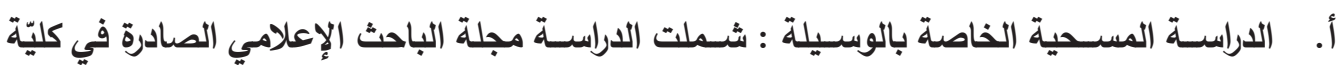

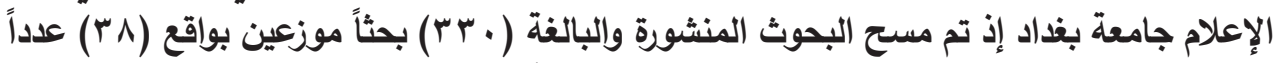

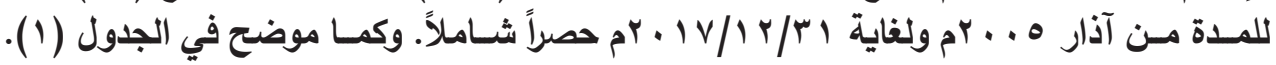
ب. عينة الدراسـة الميدانية الخاصة بالباحثين والاسـاتذة إذ بلغ حجم عينة الدراسـة الميدانية ( . . 1) أسـتاذ وباحث في الإعلام من كلا الجنسين. 
جدول (1) يبين عدد البحوث المنشـورة في عينة البحث

\begin{tabular}{|c|c|c|c|c|}
\hline الملاحظات & عدد البحوث & 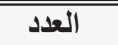 & سنة الإصدار & $\Xi$ \\
\hline إصدار عدد واحد في السنة & 9 & 1 & $r \ldots$ & 1 \\
\hline إصدار عدد واحد في السنة & 1. & $\bar{r}$ & $r \ldots q$ & $\bar{r}$ \\
\hline إصدار عدد واحد في السنة & 17 & $\bar{r}$ & $r \cdot V^{2}$ & $\bar{r}$ \\
\hline إصدار عدد واحد في السنة & IY & $\varepsilon$ & $r \cdots \Lambda$ & $\varepsilon$ \\
\hline \multirow{2}{*}{ 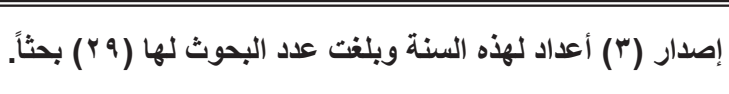 } & 10 & 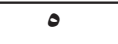 & 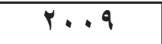 & 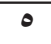 \\
\hline & $1 \varepsilon$ & V-7 & $r \ldots q$ & 7 \\
\hline إصدار (r) أعداد لهذه السنة وبلغت عدد البحوث لها (Y^) بحثًا. & 14 & 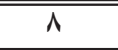 & r.1. & 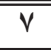 \\
\hline \multirow{4}{*}{ إصدار (乏) أعداد لهذه السنة وبلغت عدد البحوث لها (Y^) بحثاً. } & 10 & $1 \cdot-9$ & r.1. & 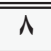 \\
\hline & 9 & $\mid Y-11$ & r. 11 & 9 \\
\hline & 9 & $1 \%$ & r. II & 1. \\
\hline & 1. & $1 \leqslant$ & T. II & 11 \\
\hline \multirow{4}{*}{ إصدار (؛) أعداد لهذه السنة وبلغت عدد البحوث لها ( • ؛ ) بحثًا. } & 11 & 10 & $F \cdot{ }^{\prime} I^{\prime}$ & $\overline{I T}$ \\
\hline & 1. & 17 & $\bar{r}+1 r$ & Ir \\
\hline & 1. & IV & 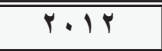 & $1 \varepsilon$ \\
\hline & 99 & 11 & r. r. r & 10 \\
\hline \multirow{4}{*}{ إصدار (ء) أعداد لهذه السنة وبلغت عدد البحوث لها ( ؛ ) بحثاً. } & 9 & 19 & r. r r & 19 \\
\hline & 9 & $r$. & $r .1 r$ & IV \\
\hline & 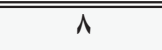 & Pr & T.Ir & 11 \\
\hline & 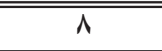 & Pr & 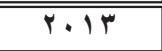 & 19 \\
\hline \multirow{3}{*}{ 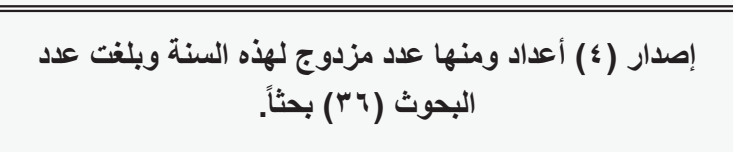 } & 9 & $r T$ & $r .1 \leq$ & $r$. \\
\hline & 19 & YO-Y & r. I & YI \\
\hline & 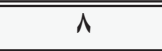 & YY & Y.1 & Pr \\
\hline \multirow{4}{*}{ إصدار (ع) أعداد لهذه السنة وبلغت عدد البحوث لها (૧ r) بحثًا. } & 9 & PrV & r.10 & Pr \\
\hline & 1. & $r \wedge$ & $r .10$ & $r \varepsilon$ \\
\hline & 1. & pq & $r .10$ & ro \\
\hline & $\mathrm{V}$ & $r$. & $r .10$ & r4 \\
\hline \multirow{3}{*}{ 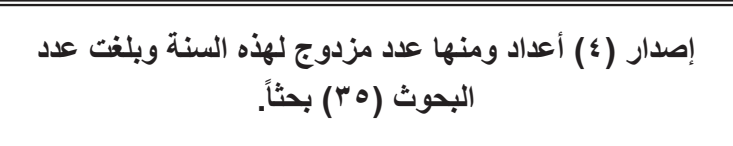 } & $\bar{V}$ & $\begin{array}{ll}1 \\
\end{array}$ & $r .19$ & TV \\
\hline & V & $r r$ & 5.17 & rA \\
\hline & 11 & $r \varepsilon-r r$ & $r .19$ & rq \\
\hline \multirow{5}{*}{ إصدار ( ) أعداد لهذه السنة ويلغت عدد البحوث لها (YV) بحثًا. } & $1 \wedge$ & ro & r.IV & $r$. \\
\hline & $\xi$ & 74 & T.IV & 41 \\
\hline & $\bar{v}$ & PrV & P.IV & "rr \\
\hline & $\bar{~} \wedge$ & rᄉ & r. IV & $\overline{c r}$ \\
\hline & • rrبحثاً & ^ז عدداً & r اسنة & مج \\
\hline
\end{tabular}




\section{سابقاً : الدراسات السابقة}

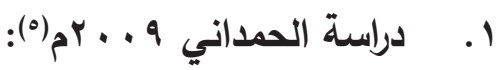

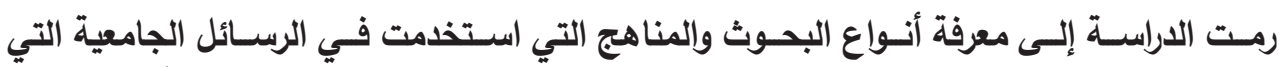

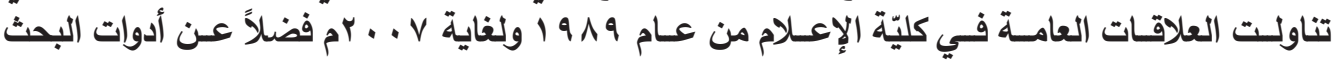

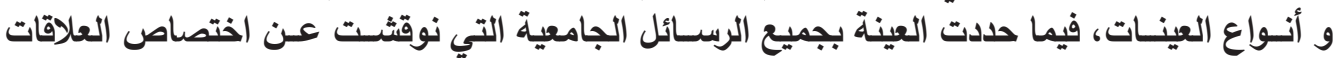

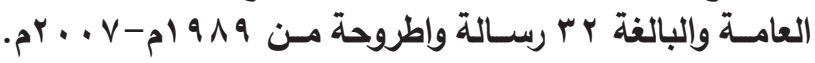

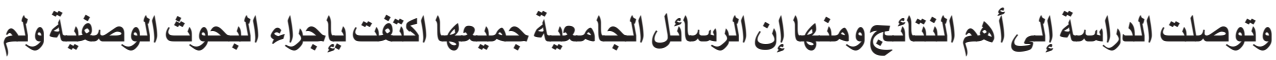
يكن هناك دراسة استكثافية أو تجريبية وتقدمت بحوث المرسل عن بحوث المستقبل والرسالة والوسيلة.

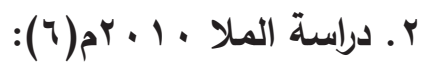

رمــت الدراسـة إلـى معرفة حـدود الرأي العلمي في بحسوث الإعلام الجماهيري وابـراز آليات التناول النظـي والتطبيقي للبحث العلىسي وكيفية الإداء البحثي.

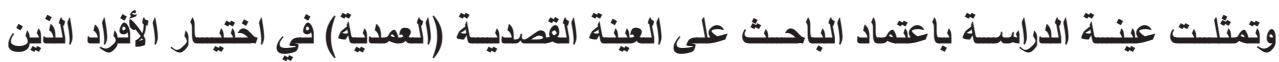

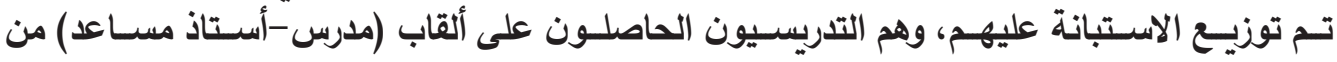

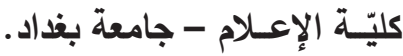

وتوصـل البحـث إلـى وجود إمكانية في تضميـن الرأي العلمي في بحوث الإعـلام وتظهر مصداقية

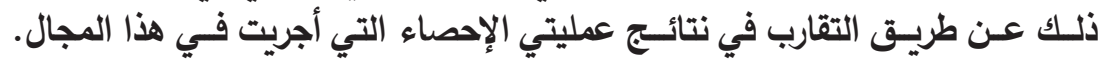

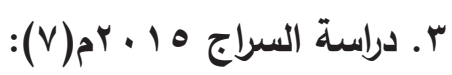

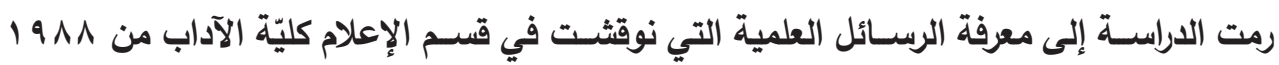

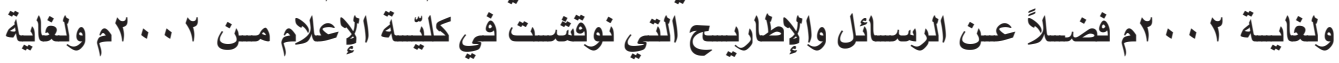

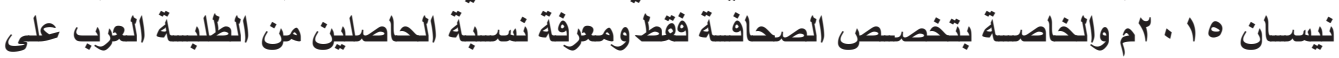

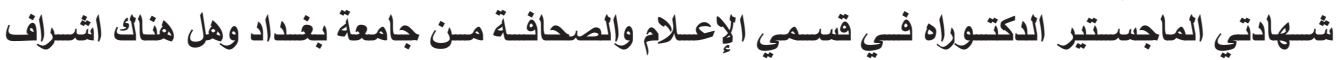

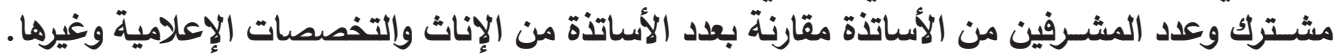

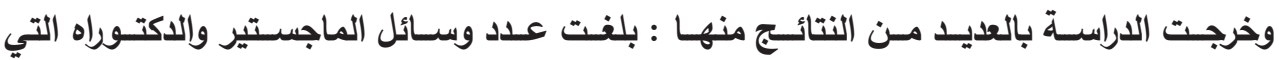

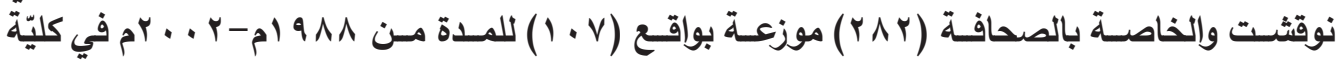

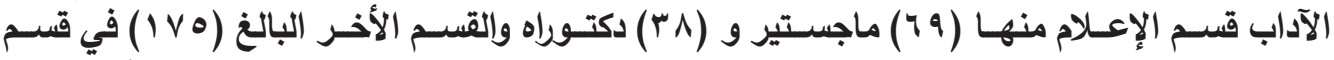

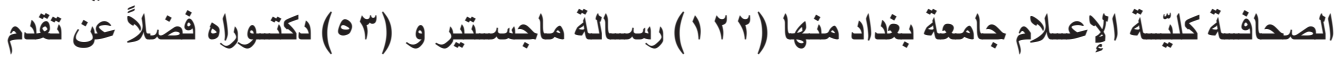

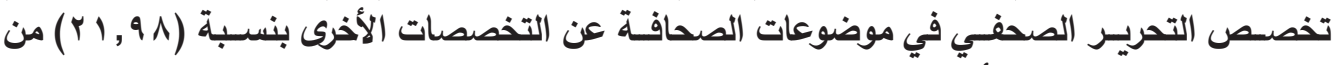
ضمسن عشـرة تخصصات أشـارت إليها الدراســة المذكورة. 


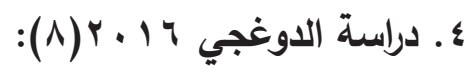

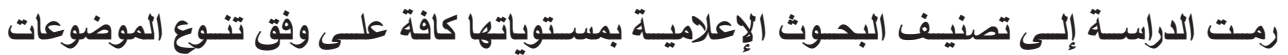

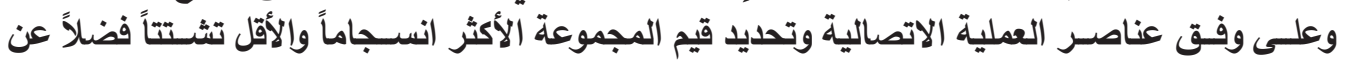

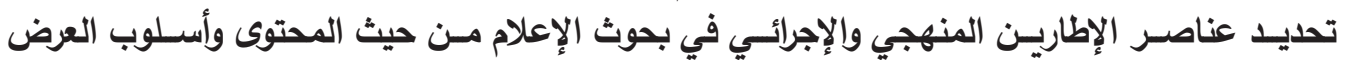

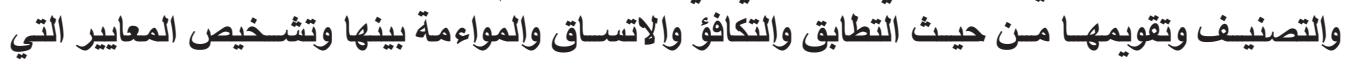
يعتمدهـا المحكمـون لتقويم مسـتوى جودة العناصر المنهجيـة والإجرائية.

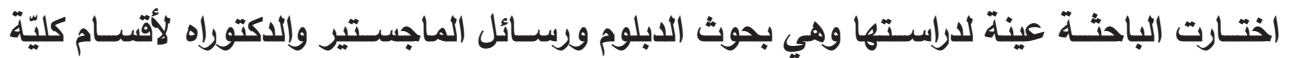

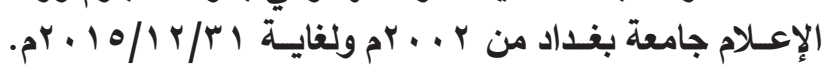

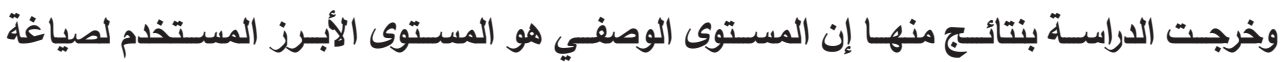

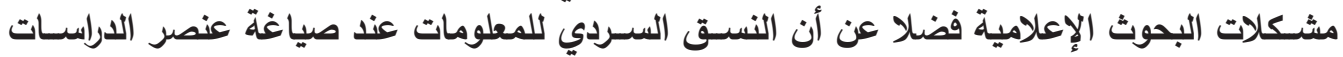

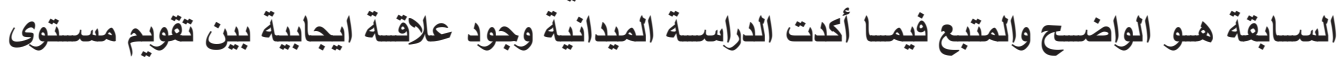

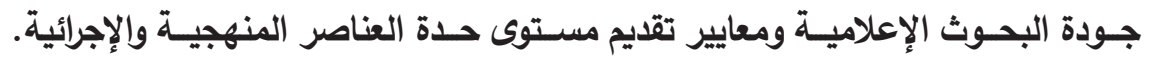

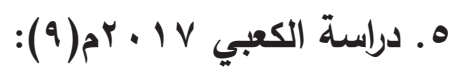

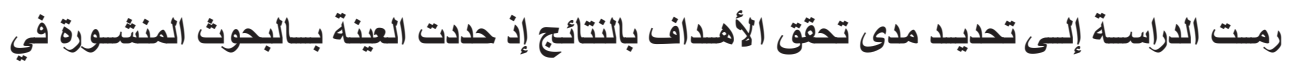

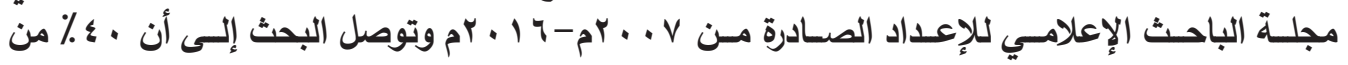

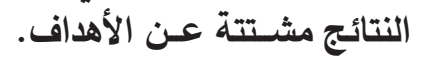
الصحافة المتخصصة والبحث العلمي وعلاقتهما بالباحث الإعلامي

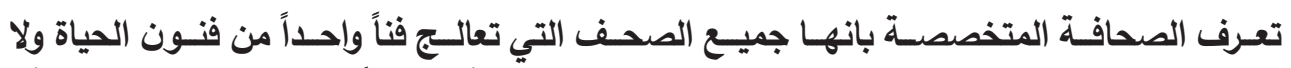

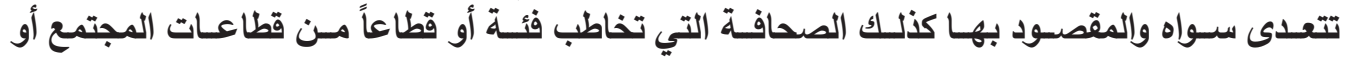
هيئة مسن هيئاته( • (1).

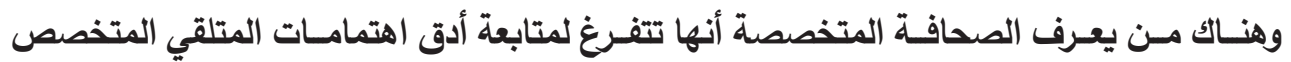

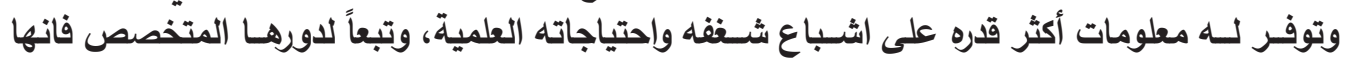

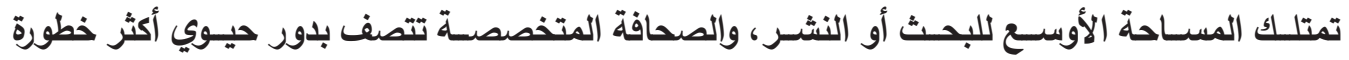

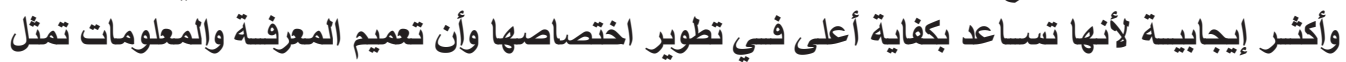

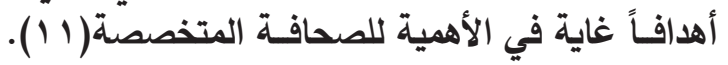

\section{أركان الصحافة المتخصصة ومستوياتها}

تقـوم الصحافـة المتخصصـة على ركنين أساسـين أولهما المــادة الصحفية المتخصصــة وثانيهما

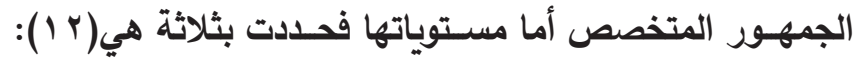

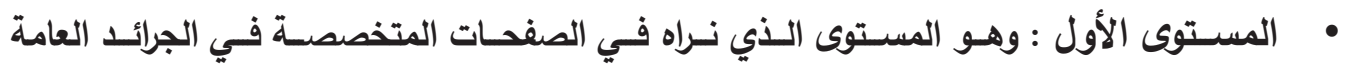




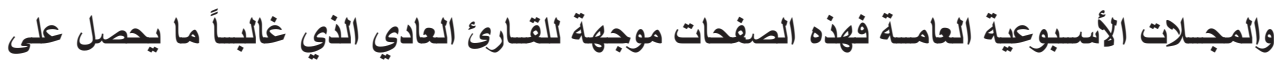

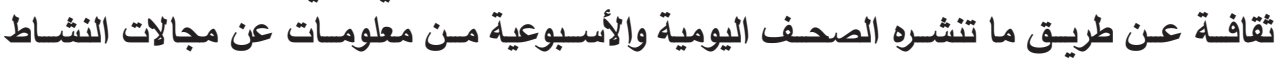

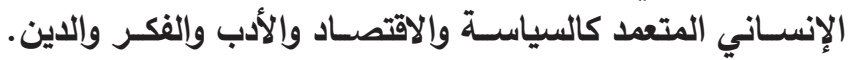

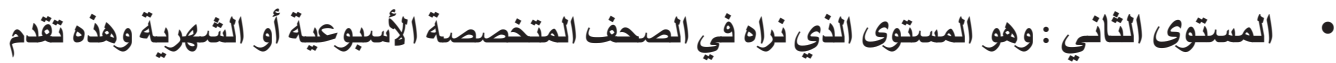
مادتها للقارئ ذي المستوى الثقافي الذي لاني يكتفي بما تنشره الصحف العادي العامة اليومية أو الأسبوعية.

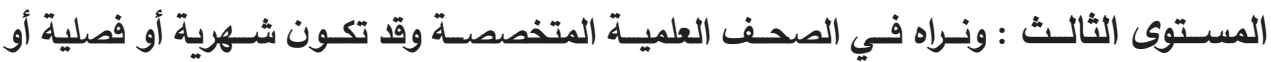

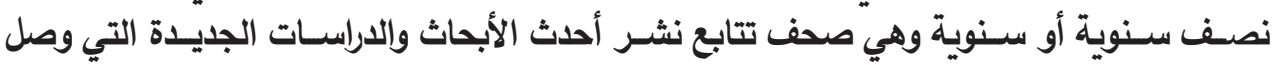

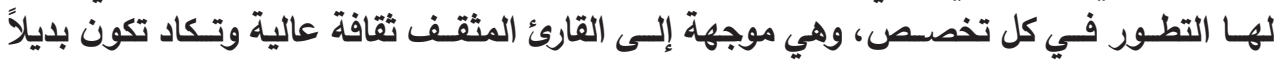

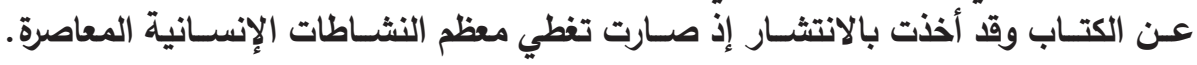

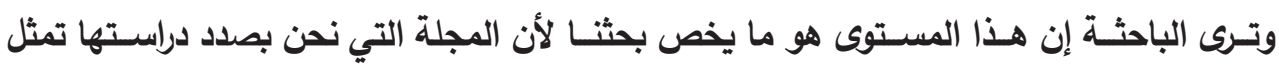

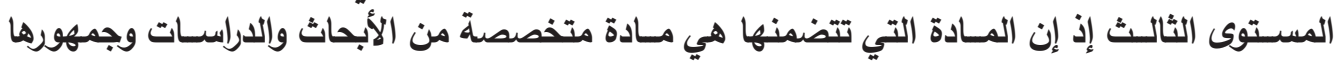

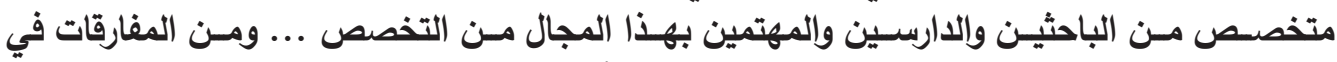

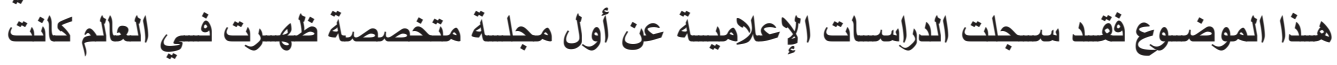

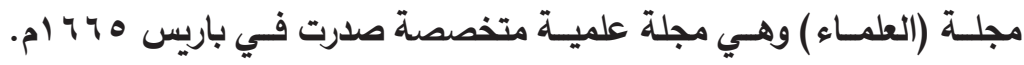

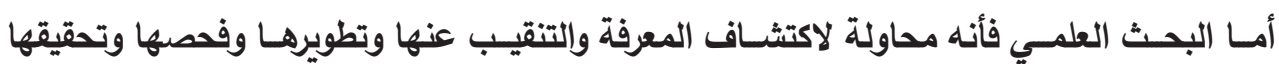

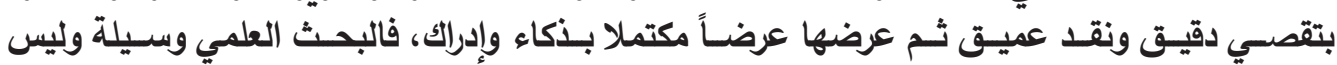

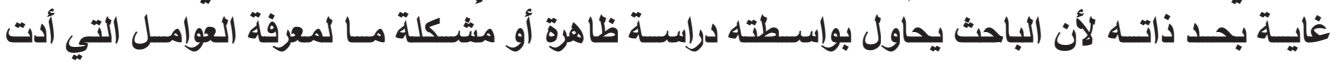

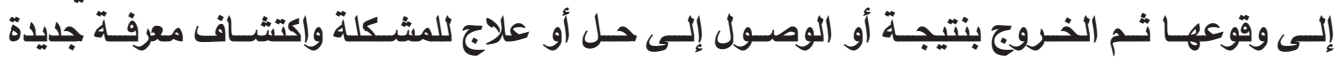

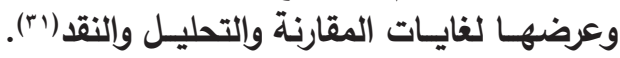

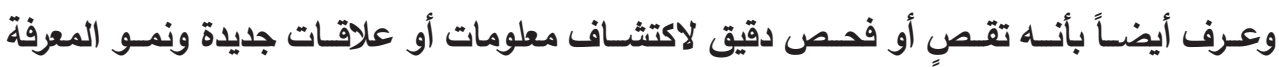

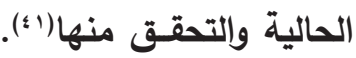

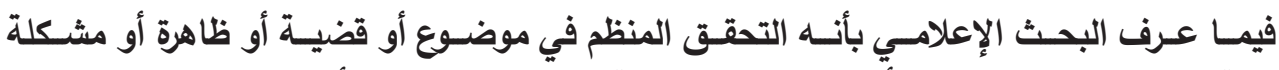

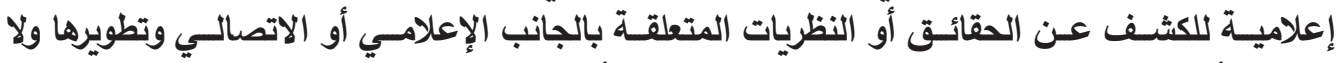

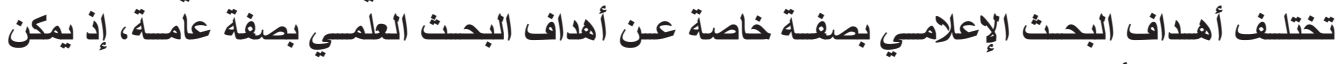
تلخيـص تلك الأهـداف بالآتي: الإعلافي 1. الكثف عن الحقائق وخصائصها. r. الكثف عن العلاقات الارتباطية لهذه الحقائق وعناصرها. r. السيطرة على حركة الحقائق التي تم اكتثافها ومعرفة خصائصها وعلاقاتها.

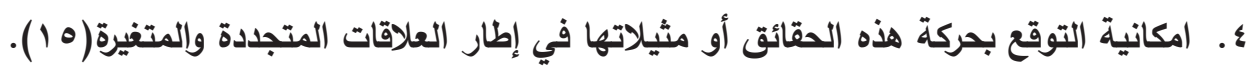




\section{مجلة الباحث الإعلامي}

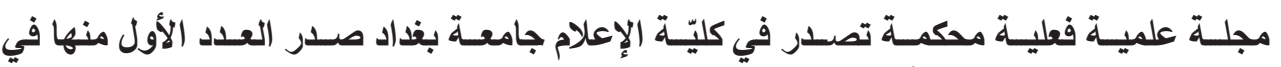

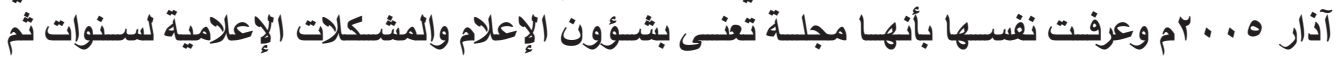

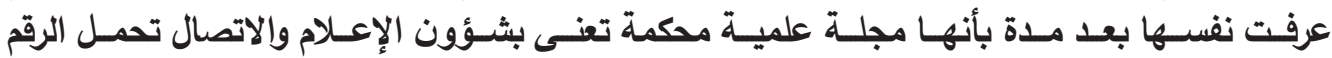

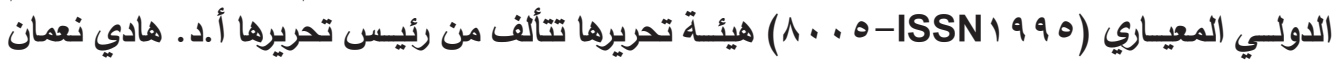

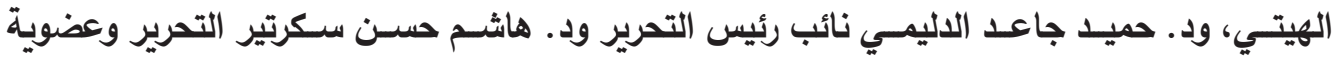

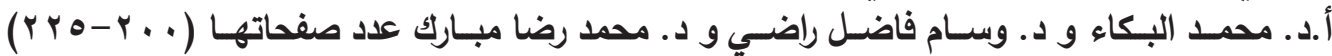

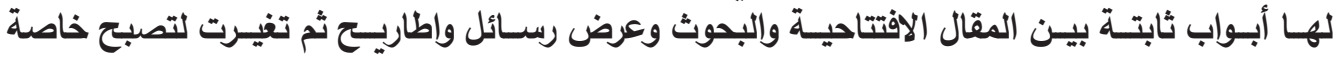

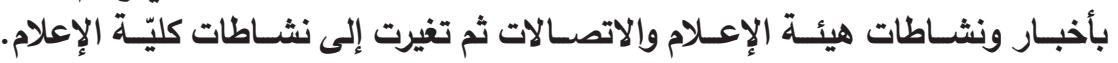

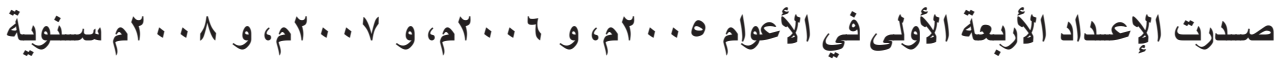

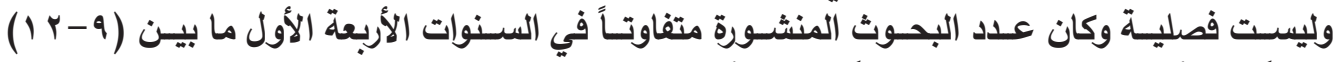

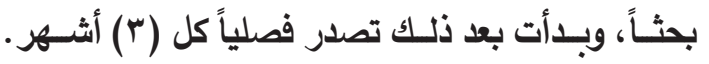

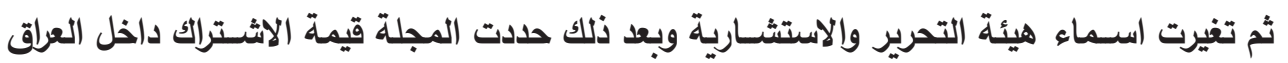

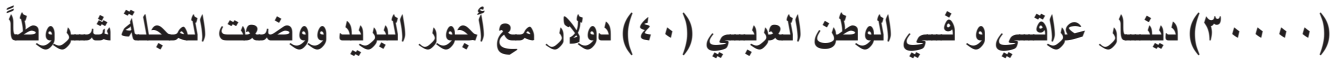

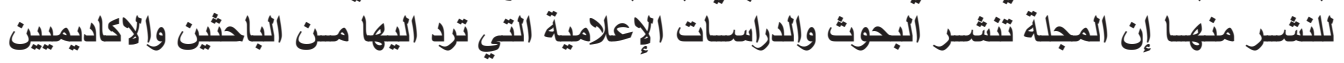

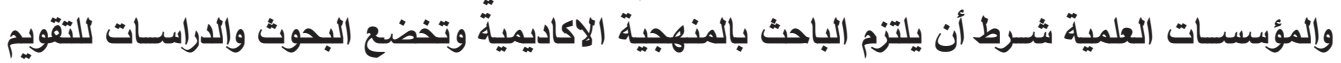
مسن محكميـن علمييـن متخصصين فضلا عن شـروط أخر واردة في كل المجـلات العلمية المحكمة.

\section{الإطار العملي للبحث}

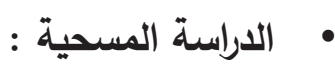

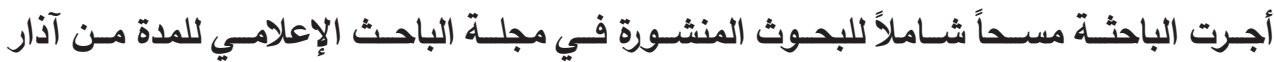

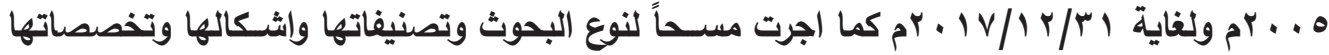

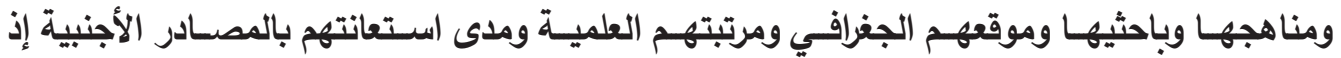

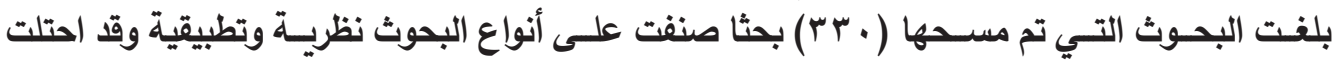

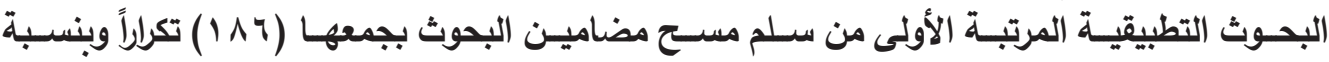

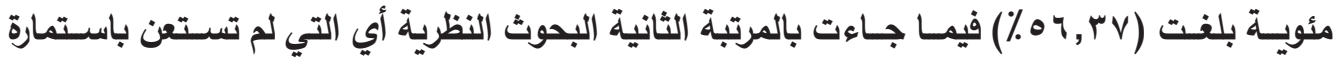

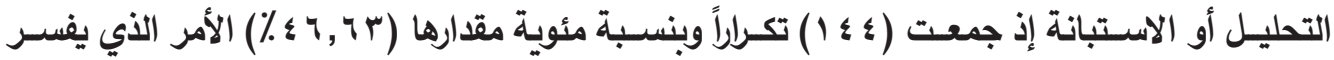

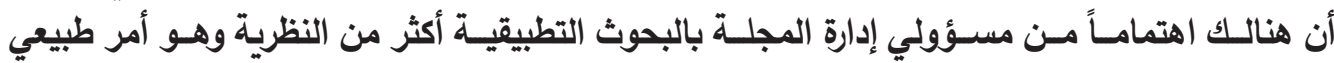

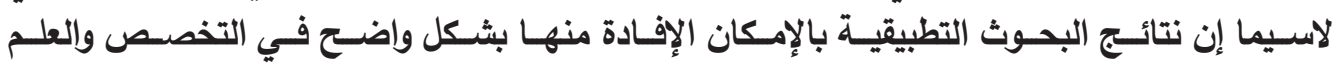

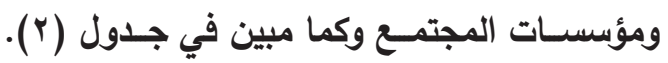


جدول (r) يبين التوزيع النسـبي لنوع وتصنيفات البحوث المنشـورة في مجلة الباحث الإعلامي من

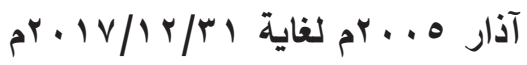

\begin{tabular}{|c|c|c|c|c|}
\hline المرتبة & النسبة \% & التكرار & نوع وتصنيف البحث & $ت$ \\
\hline الأولى & $\% \Delta 4, r v$ & 114 & البحوث التطبيقية & 1 \\
\hline الثانية & $\%\{r, \uparrow \mu$ & $1 \leqslant \varepsilon$ & البحوث النظرية & $r$ \\
\hline & $\% 1 \ldots$ & rT. & المجموع & \\
\hline
\end{tabular}

أما أشـكال البحوث المنشـورة في مجلة الباحث الإعلامي من منفردة، مشـتركة، مسـتلة فيوضحها

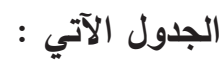

جدول (r) يبين التوزيع النسـبي لأثـكال البحوث المنشـورة في مجلة الباحث الإعلامي من آذار

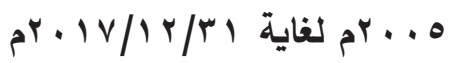

\begin{tabular}{|c|c|c|c|c|}
\hline المرتبة & النسبة \% & التكرار & شكل البحوث & $ت$ \\
\hline الأولى & $\% \vee \vee q, r q$ & ryr & بحث منفرد & 1 \\
\hline الثانية & $\% 1 \leqslant, \wedge \bullet$ & $\varepsilon q$ & بحث مشترك & $\bar{r}$ \\
\hline الثالثة & $\% \bullet, \vee ५$ & 19 & بحث مستل & $\bar{T}$ \\
\hline & $\%$ & Trr. & مجموع & \\
\hline
\end{tabular}

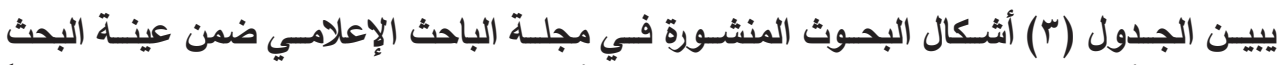

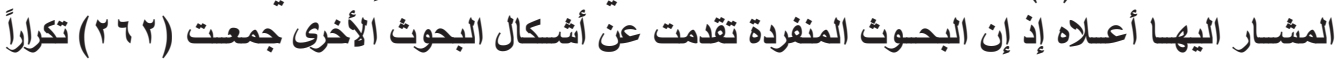

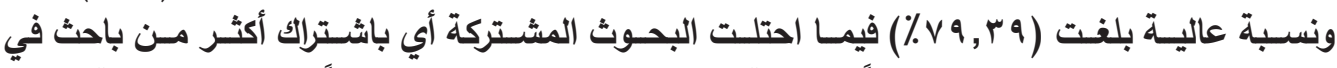

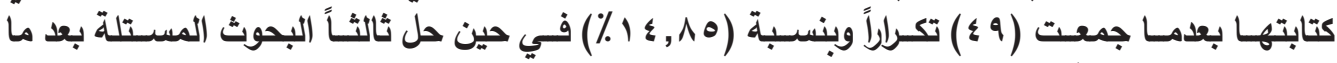

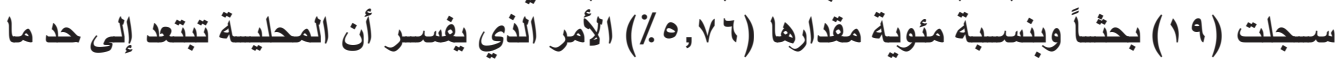

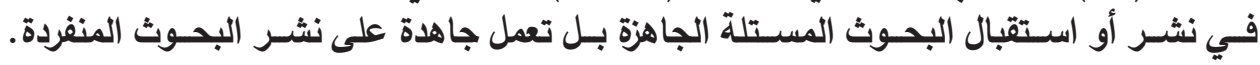
أما تخصصات البحوث المنشورة في مجلة الباحث الإعلامي فيوضحها الجدول الآتي: جدول (؛) يبين التوزيع النسـي لنوع التخصصات البحوث المنشـورة في مجلة الباحث الإعلامي

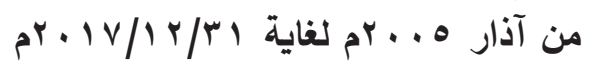

\begin{tabular}{|c|c|c|c|c|}
\hline المرتبة & النسبة \% & التكرار & التخصص & ت \\
\hline الأولى & $\% \curlyvee \wedge, 1 \wedge$ & 94 & الإعلام” & 1 \\
\hline الثانية & $\%$ \%०,V४ & 10 & صحافة & $\overline{T r}$ \\
\hline الثالثة & $\%$ \%r, ,. & 97 & الصحافة الإذاعية والتلفزيونية & $\bar{r}$ \\
\hline الرابعة & $\% 17,74$ & $\theta 0$ & العلاقات العامةة & $\varepsilon$ \\
\hline الخامسة & $\% \varepsilon, \wedge \varepsilon$ & 17 & اللغذة العربية و الإعلامية & 0 \\
\hline \multirow[t]{2}{*}{ السادسة. } & $\% \leqslant, 04$ & 10 & أخرى * & 7 \\
\hline & $\% 1 \ldots$ & rr. & المجموع & \\
\hline
\end{tabular}




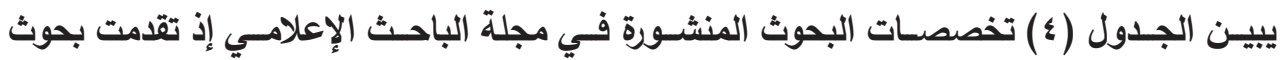

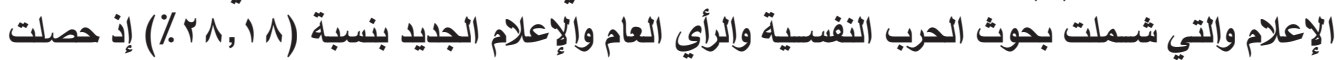

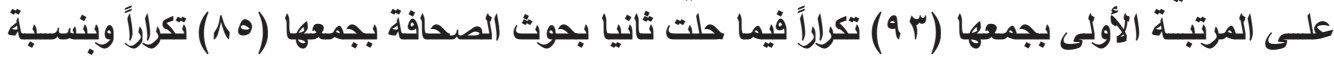

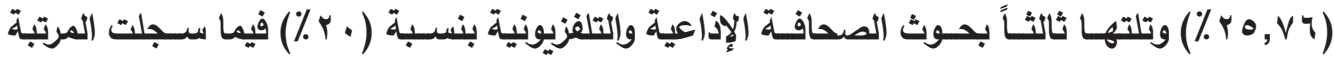

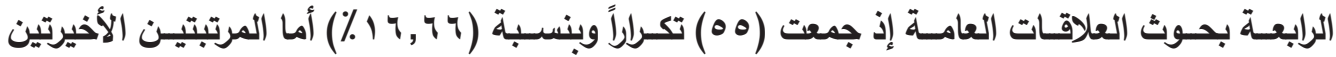

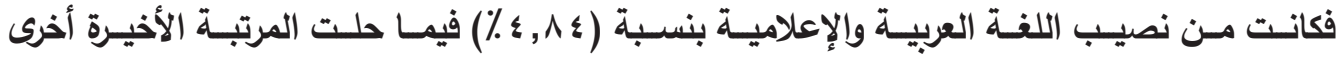

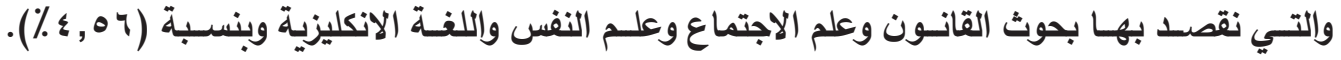
أما أنواع المناهج المستعملة في البحوث المنثورة في مجلة الباحث فيوضحها جدول(ه). جدول (•) يبين التوزيع النسبي لنوع المناهج المسـتعملة للبحوث المنشـورة في مجلة الباحث

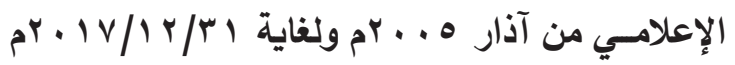

\begin{tabular}{|c|c|c|c|c|}
\hline المرتبة & النسبة \% & التكرار & نوع المنهج & 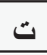 \\
\hline الأولى & $\% 04, r v$ & 114 & المسحي & 1 \\
\hline الثانية & $\% 44,97$ & Irr & الوصفي & $r$ \\
\hline الثالثة & r זו, & Ir & التاريخي & $r$ \\
\hline \multirow[t]{2}{*}{ الر ابعة } & $\% \mu, \cdot r$ & 1. & أكثر من منهج & $\varepsilon$ \\
\hline & $\% 1 \ldots$ & קr. & لمجموع & \\
\hline
\end{tabular}

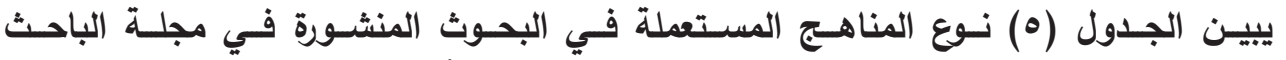

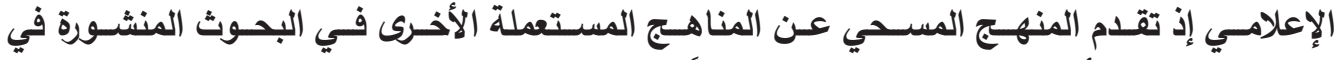

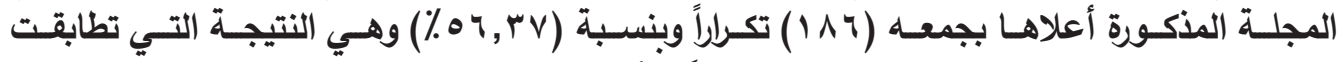

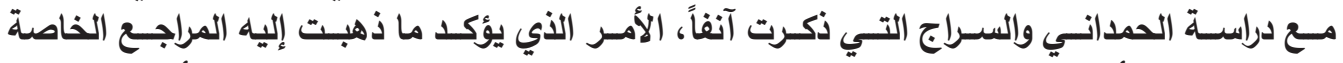

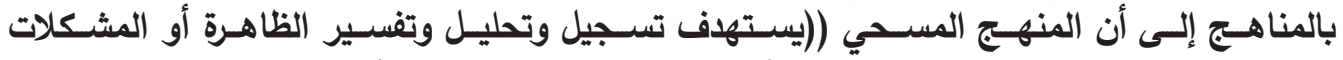

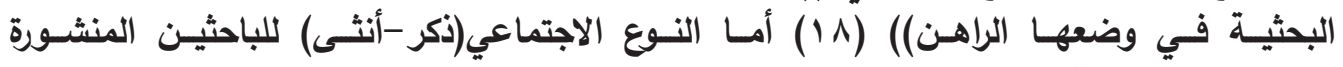

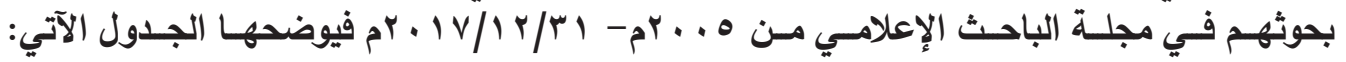
جلول (†) يمثل التوزيع النسبي للنوع الاجتماعي للباحثين المنشـورة بحوثهم في المجلة أعلاه

\begin{tabular}{|c|c|c|c|c|c|c|c|c|c|c|c|c|c|c|}
\hline$\underline{\underline{\xi}}$ & $\frac{b}{b}: \frac{1}{2}$ & $\frac{6}{5}=$ & $\frac{L}{b}:$ & $\frac{6}{b}:$ & $\frac{L}{b}:$ & $\frac{b}{b}:$ & $\frac{L}{b}:$ & $\frac{6}{5}:$ & $\frac{6}{b}:$ & $\dot{3}$ & $\dot{2}$ & $\vdots$ & $\vdots$ & $\underline{\underline{E}}$ \\
\hline Yos & $1 \varepsilon$ & Yr & rr & r. & rA & $r \wedge$ & $r \varepsilon$ & 11 & 11 & $\wedge$ & 10 & $\wedge$ & $\wedge$ & ذكر \\
\hline 1.1 & $\wedge$ & $q$ & 11 & 11 & $1 \varepsilon$ & $1 \varepsilon$ & $\wedge$ & 11 & 11 & 0 & $r$ & r & 1 & أنثى \\
\hline *** & YY & rI & \& $\leqslant$ & «1 & $\varepsilon r$ & $\varepsilon r$ & rY & rq & rq & ir & 11 & 1. & 9 & مج \\
\hline
\end{tabular}




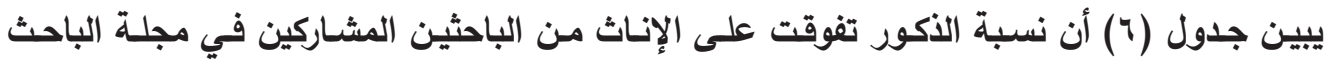

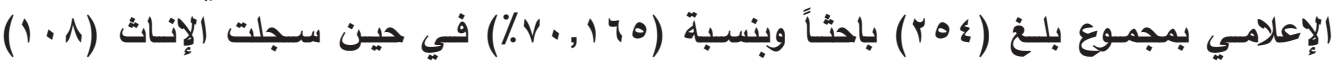

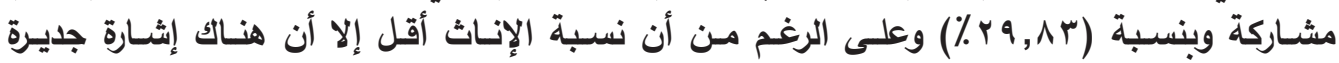

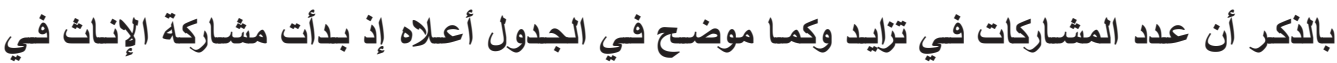

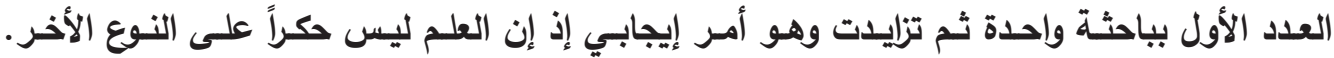

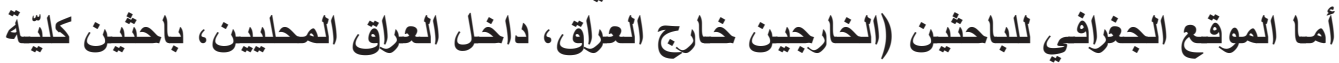

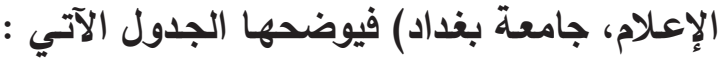

جدول (V) يبين التوزيع النسبي للموقع الجغرافي للباحثين المنشـورة في مجلة الباحث عينة البحث

\begin{tabular}{|c|c|c|c|c|}
\hline المرتبة & النسبة \% & التكرار & الموقع الجغرافي للباحثين**** & $ت$ \\
\hline الأولى & $\% ० q, r q$ & 199 & الباحثُون من كليَّة الإعلام جامعة بغذاد. & 1 \\
\hline الثانية & $\%(r, 1 \wedge$ & 1.0 & الباحثُون المحليون (داخل العراق) & r \\
\hline \multirow[t]{2}{*}{ الثالثة } & $\% \wedge, \vee \wedge$ & rq & الباحثُون الخارجيون (خارج العراق) & $r$ \\
\hline & $\% 1 \ldots$ & $r \mu$. & 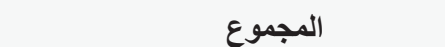 & \\
\hline
\end{tabular}

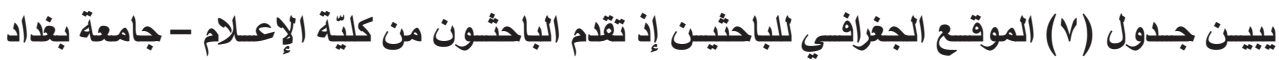

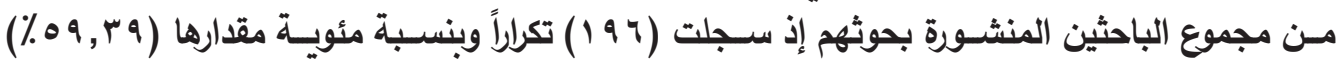

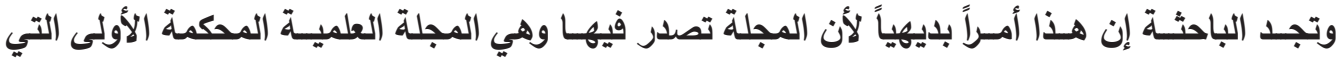

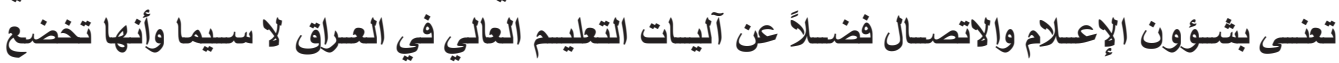

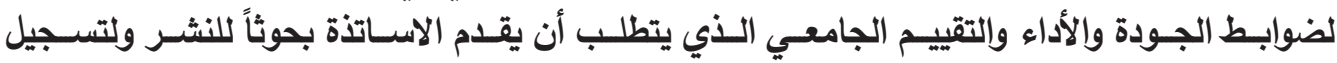

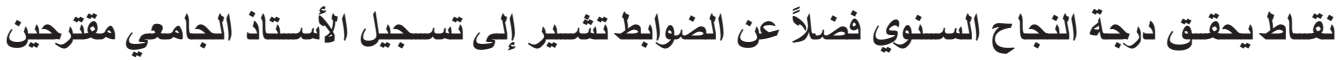

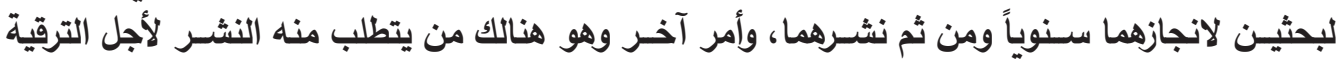

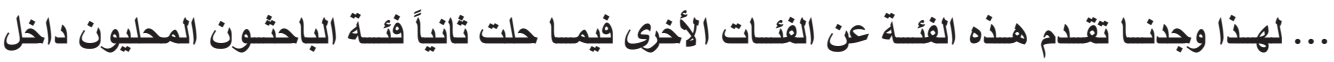

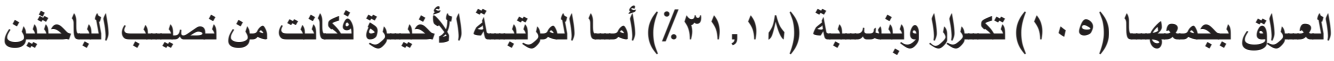

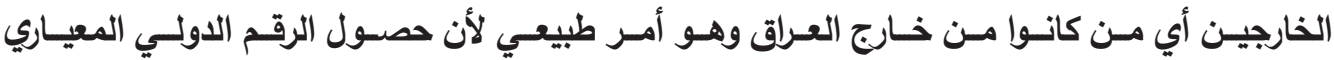

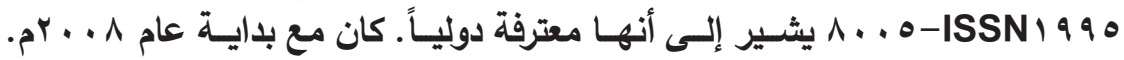
أمـا المرتبـة العلميـة (الارجـة العلمية) للباحثين المشــاركين فـي مجلة الباحـث الإعلامي فيمثلها الجـدول الآتي : 


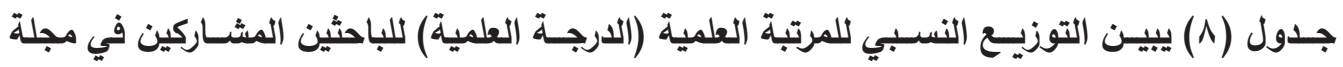

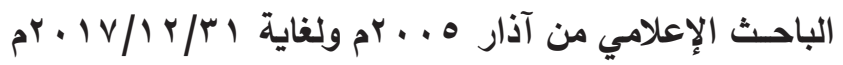

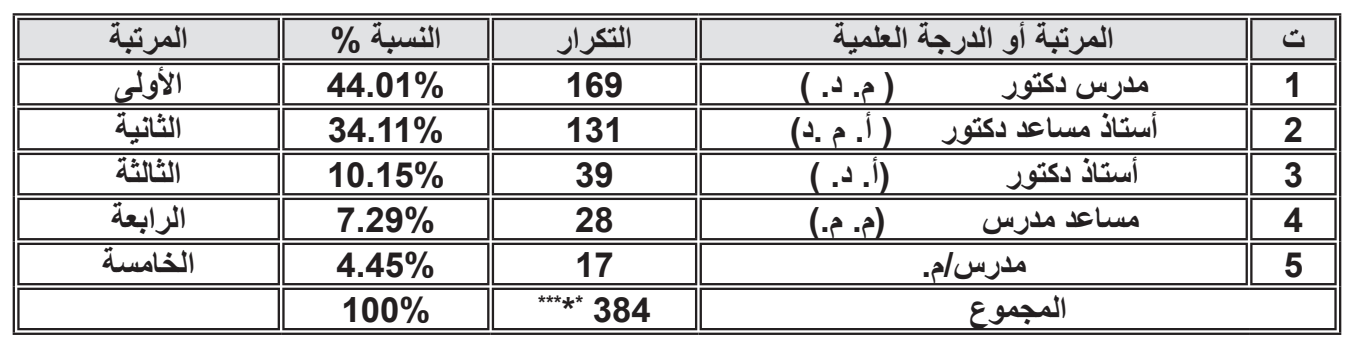

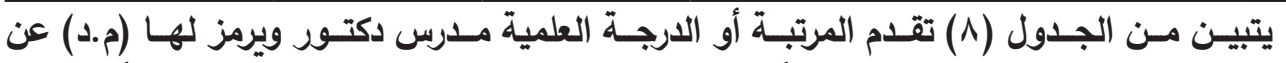

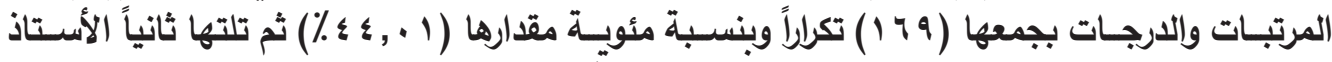

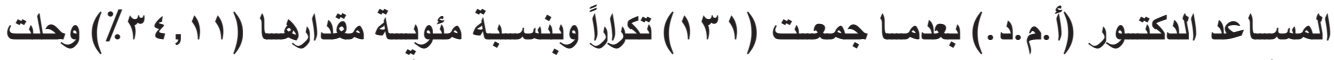

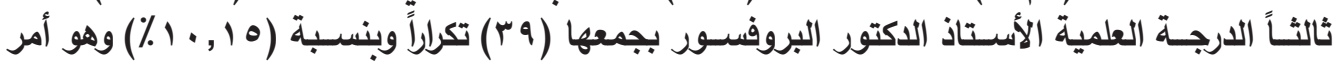

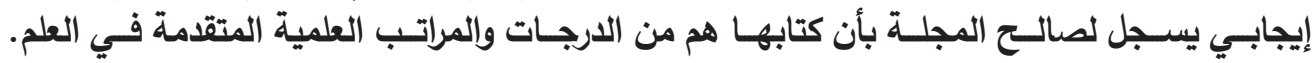
وعن مدى استعمالات الباحثين المصادر ونوع اللغة ونسبة ذلك الجدول (9) يوضح ذلك. جـدول (9) يبيـن التوزيــع النسـبي لاسـتعمالات الباحثيـن للمصادر ونـوع اللفة للبحوث المنشـورة في مجلة الباحث الإعلامي

\begin{tabular}{|c|c|c|c|c|}
\hline المرتبة & النسبة \% & التكرار - - ار & المصادر ونوع اللغة & $ت$ \\
\hline 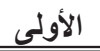 & $\%$ \%,$\wedge \mathrm{V}$ & rYs & استعمال المصادر العربية فقط. & 1 \\
\hline الثانية & \%rr, rr & vV & استعمال ربع مصادر البحث باللغة الانكليزية. & r \\
\hline الثالثة & $\%$ \% rV & $r \varepsilon$ & استعمال أكثر من نصف مصادر البعث باللغة الانكليزية. & r \\
\hline \multirow[t]{2}{*}{ الر ابعة } & $\% 1,01$ & $\bullet$ & استعمال المصادر البحث كلها باللغة الانكليزية. & $\varepsilon$ \\
\hline & $\% 1 \ldots$ & rr. & المجموع & \\
\hline
\end{tabular}

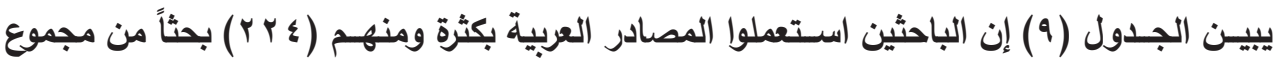

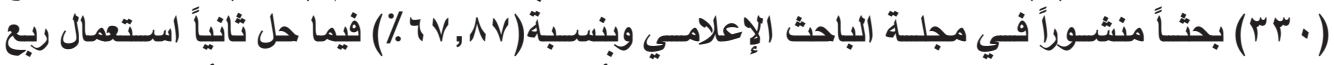

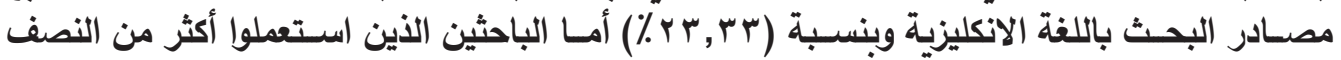

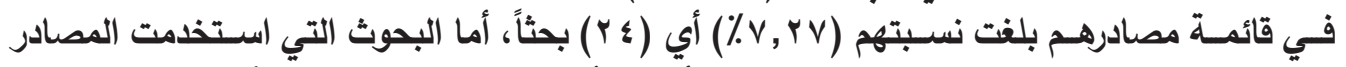

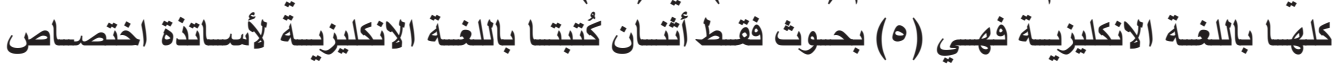

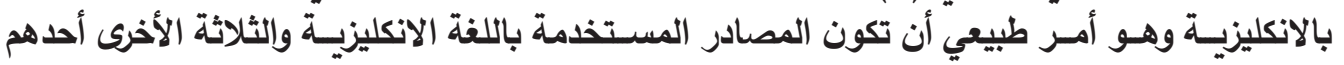

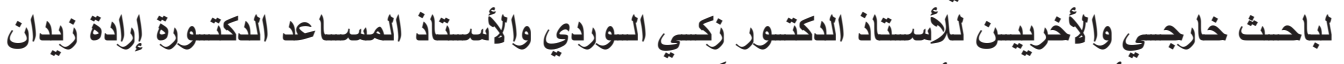

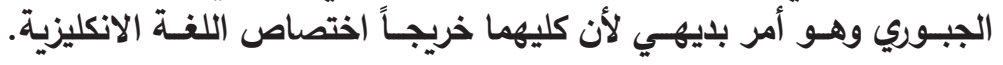


أمسا فيمـا يخـص مدى اعتماد البحوث المنشـورة نظرية إعلامية تمت الإثـــارة اليها بثـكل واضح فيوضحهـا الجدول الآتي: جـدول ( • 1) يبيـن التوزيـع النسـبي لاسـتعمالات الباحثيـن لنظرية إعلاميـة في بحوثهم المنشـورة

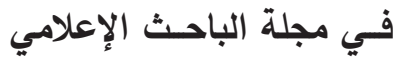

\begin{tabular}{|c|c|c|c|c|}
\hline المرتبة & النسبة \% & التكرار الت & بيان الموقف من الاستعمال & $ت$ \\
\hline الأولى & $\%$ \% ฯ ฯ & r^צ & بحوث لم تستخدم نظرية إعلامية. & 1 \\
\hline \multirow[t]{2}{*}{ الثاتية } & \% & $\varepsilon \varepsilon$ & بحوث استخدمت نظرية إعلامية & r \\
\hline & $\% 1 \ldots$ & rr. & المجموع & \\
\hline
\end{tabular}

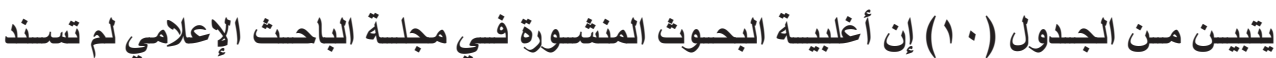

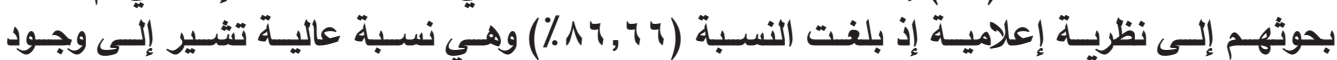

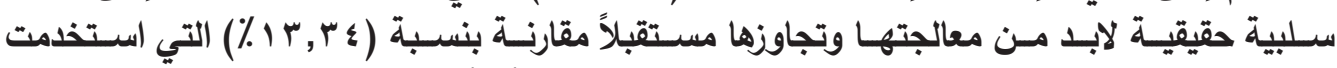

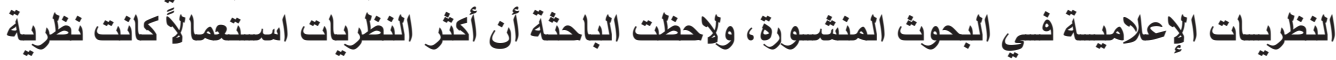

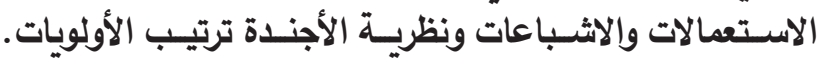

\section{أ. الدراسة الميدانية}

العناصر التبوغرافية :

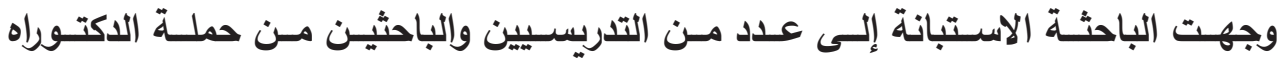

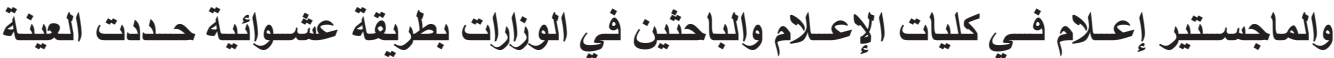

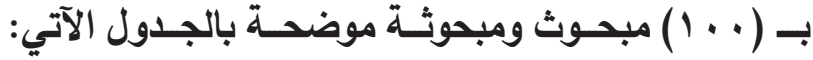
جـول (11) يوضـح التوزيع النسـبي العينة العشـوائية البسـيطة للتدريسـيين والباحثيـن من حملة الثــهادات العليـا في الإعلام

\begin{tabular}{|c|c|c|c|}
\hline النسبة \% & التكرار & الشهادة & $ت$ \\
\hline$\% 1 \wedge$ & 71 & دكتوراه إعلام & 1 \\
\hline$\% r r$ & rr & ماجستير & $r$ \\
\hline$\% 1 \ldots$ & $1 \ldots$ & لمجموع & \\
\hline
\end{tabular}

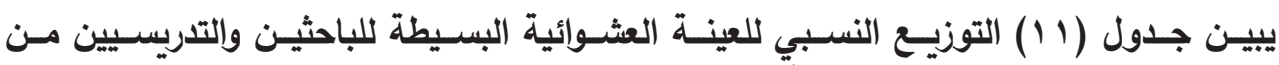

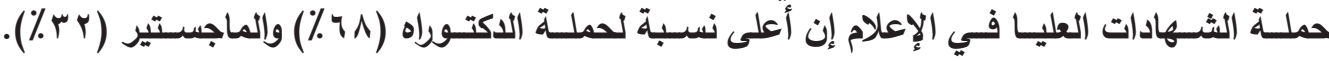
جدول (r ا ) يوضح التوزيع النسبي للمبحوثين من التدريسيين والباحثين على وفق النوع الاجتماعي 


\begin{tabular}{|c|c|c|c|c|c|c|c|}
\hline \multirow{3}{*}{ النسبة \% } & \multirow{3}{*}{ المجموع } & \multicolumn{4}{|c|}{ النوع الاجتماعي } & \multirow{3}{*}{ الشهادة } & \multirow{3}{*}{$ت$} \\
\hline & & \multicolumn{2}{|c|}{ الإناث } & \multicolumn{2}{|c|}{ الأكور } & & \\
\hline & & $\%$ & ك & $\%$ & ك & & \\
\hline$\%$ & 71 & $r \wedge, r \varepsilon$ & rq & 71,87 & $\varepsilon r$ & دكتور اه إعلام & 1 \\
\hline$\% r r$ & rr & $\varepsilon r, v \uparrow$ & $1 \varepsilon$ & $r q, r_{0}$ & 11 & ماجستير & r \\
\hline$\% 1 \ldots$ & $1 \ldots$ & - & $\varepsilon$. & - & 7. & المجموع & \\
\hline
\end{tabular}

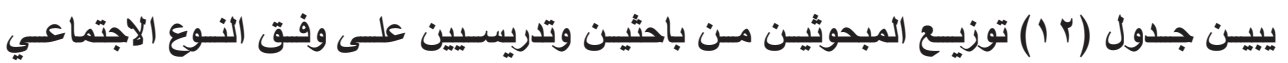

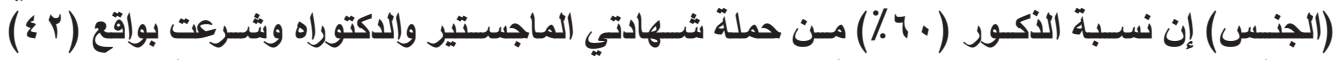

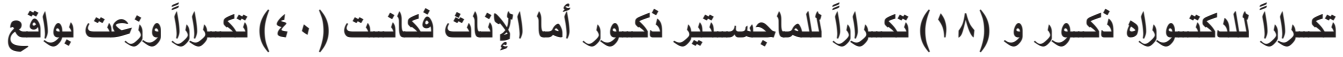

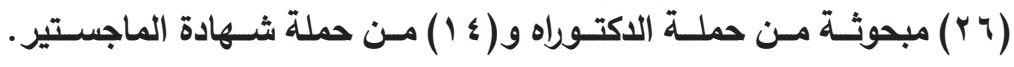

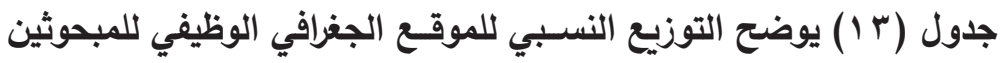

\begin{tabular}{|c|c|c|c|}
\hline النسبة \% & التكرار & الموقع الوظيفي & $ت$ \\
\hline$\%$ or & or & تدريسيو كليّة الإعلام جامعة بذاد & 1 \\
\hline$\% r r$ & rr & تدريسيو كليّة الإعلام العراقية & $r$ \\
\hline$\% 14$ & 17 & باحثو دوائر الدولة & 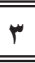 \\
\hline$\% 1 \ldots$ & $1 \ldots$ & 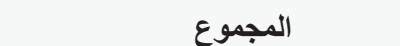 & \\
\hline
\end{tabular}

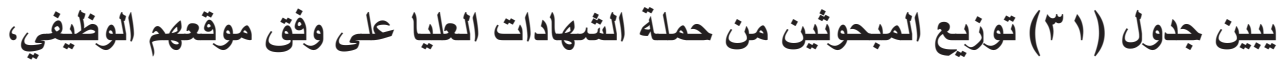

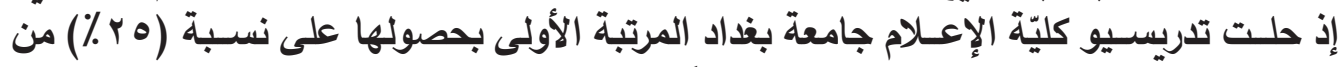

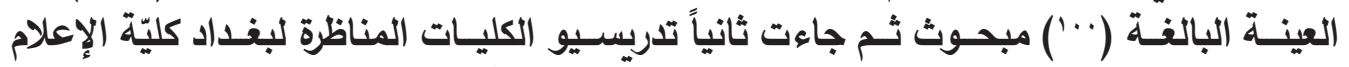

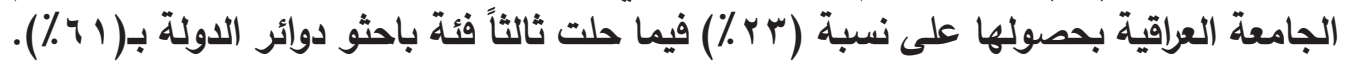

\section{أسئلة الاستبانة}

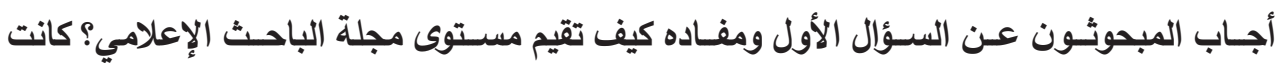

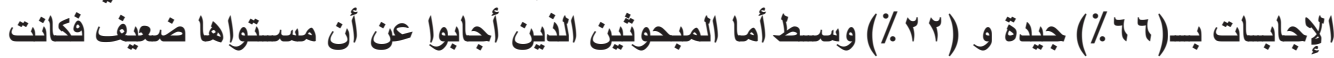

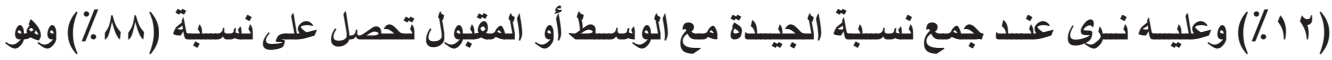

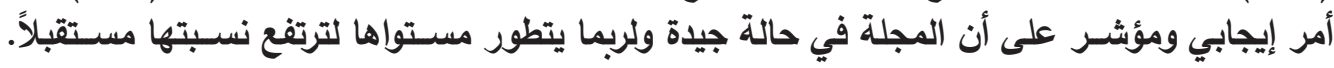

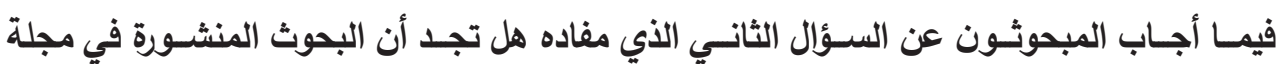

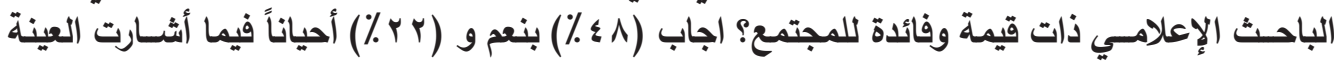

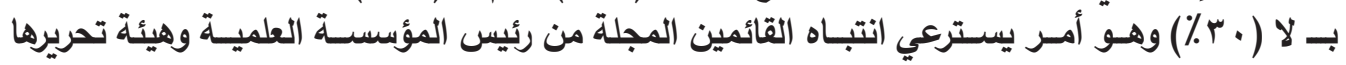

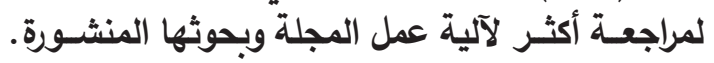
أمـا السـؤال الثالـث والذي مفاده هـل تجد أن البحوث المنشــورة في مجلة الباحـث الإعلامي ذات 


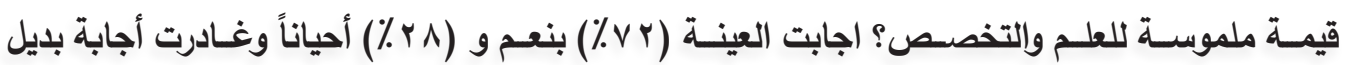

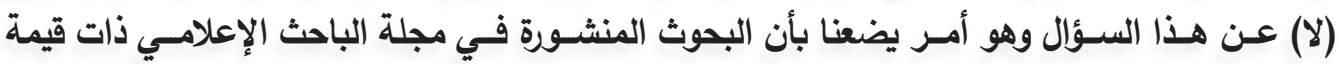

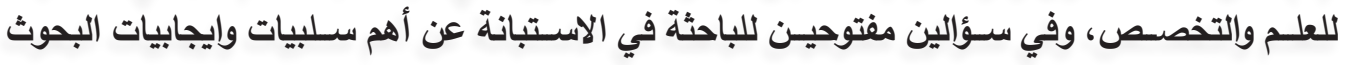

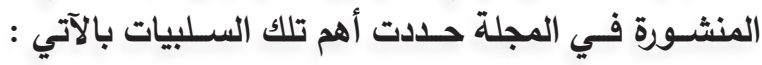

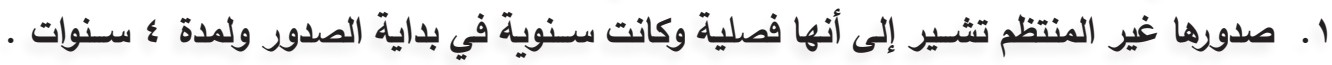

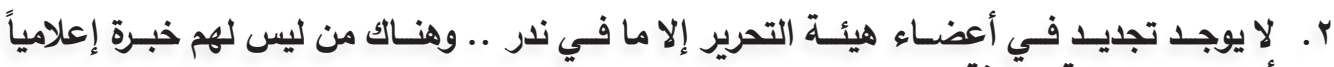

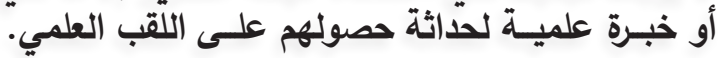

r. عـدم تطابـق اغلب عناوين البحوث مع المضمون ومثال على ذلك بحوث منشـورة في العدد 9 ـ ـ

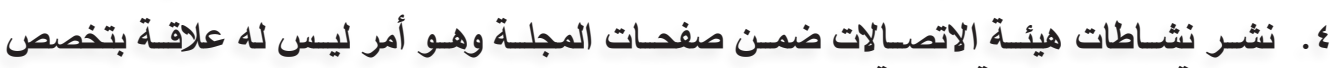
المجلـة كونهـا علميـة محكمة.

ه. غلبة الاعتماد على المصادر العربية عن الانكليزية في اغلب البحوث. 4. . هناك محاباة في نشر البحوث ... إذا ما كان الاسم معروفاً فينشر حتى ولو كان البحث غير موفق. V. غياب عدد من فقرات المنهجية في الإطار المنهجي للبحث. ^. تحديد الباحث بعدد صفحات البحث.

9 ـ فيما أثشار المبحوثون إلى أهم إيجابيات المجلة. • 1 .ملحوظة جديرة بالذكر تقدم وتطور المجلة من حيث الأخراج.

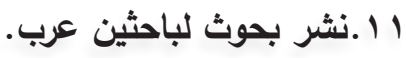
r ا ا.وجود ملخصات باللغة الانكليزية لكل بحث. rا 1 .وفي السؤال الأخير قدمته الباحثة للمبحوثين مفاده. ؛ 1 ـهل أنت راضٍ عن مجلة الباحث الإعلامي؟

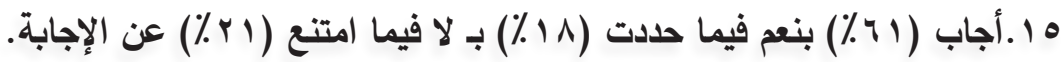




\section{النتائج}

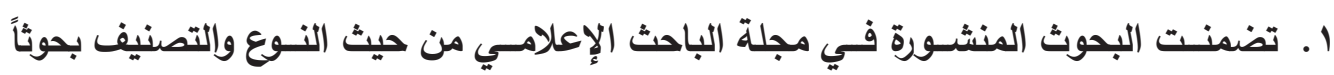

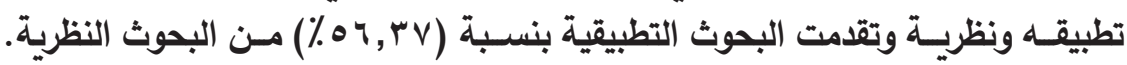

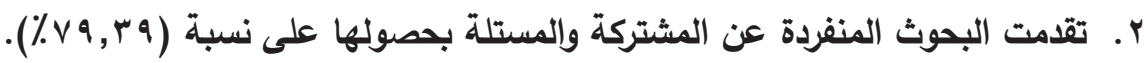

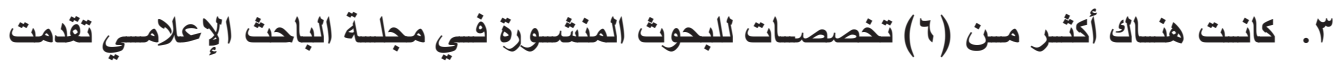

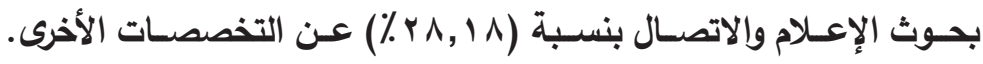

؛. تقام المنهج المسـي عن المناهج المستعملة في البحوث المنشـورة في مجلة الباحث الإعلامي

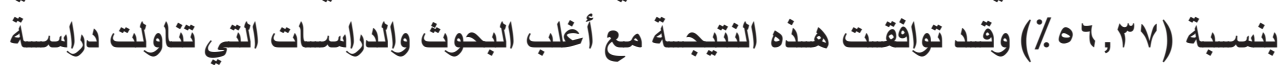

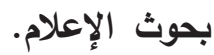

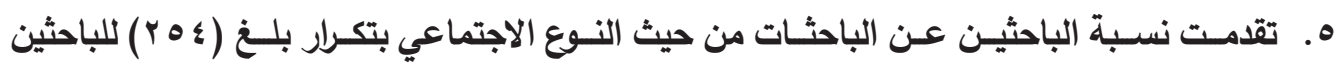

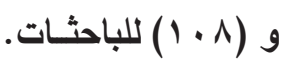

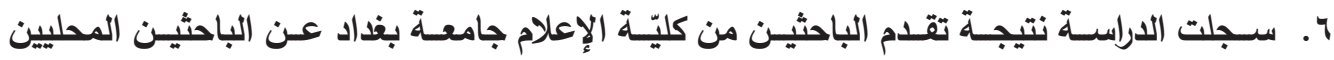

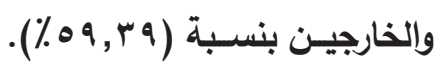

V. تقدم الارجة العلمية (مدرس دكتور) من الارجات الأخرى بتسجيلها نسبة (1 . , ؛ ؛ ٪).

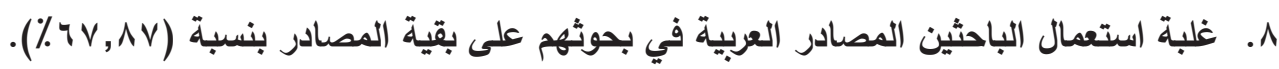

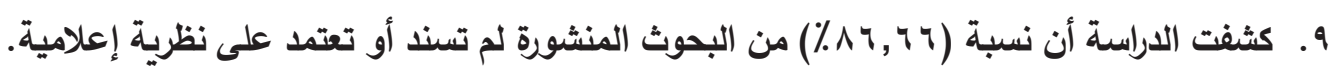

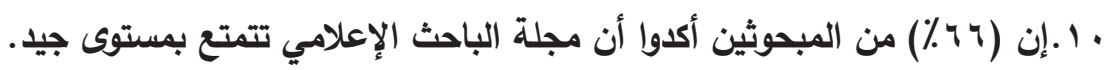

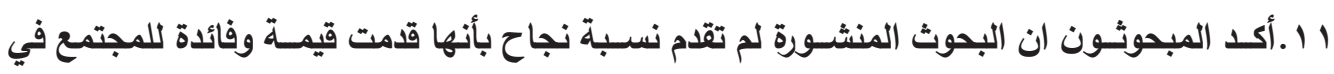

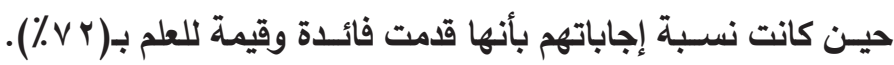

r r r ا.شخص المبحوثون العديد من السلبيات فضلاً عن الإيجابيات.

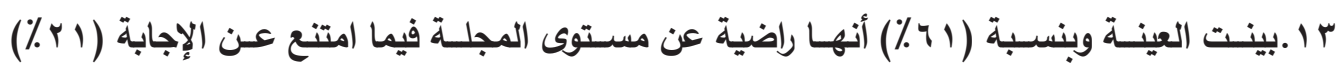
ومهـا تبقى كانـت اجابتهم بـ لا.

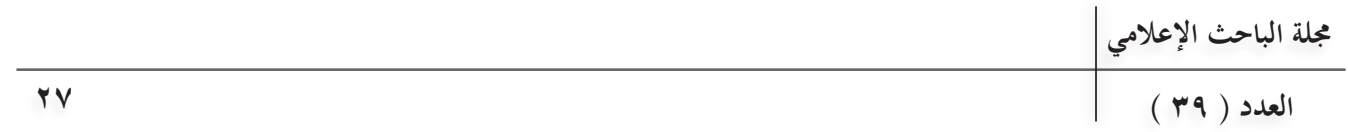




\section{الهوامش والمصادر}

(setondnE)

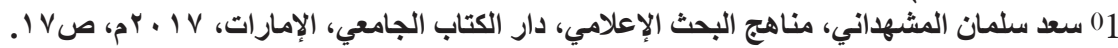

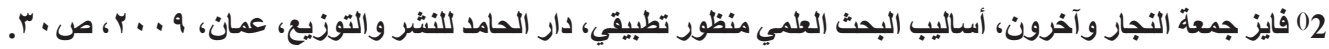

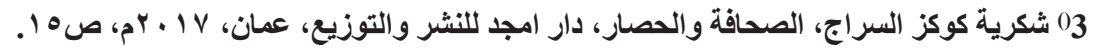

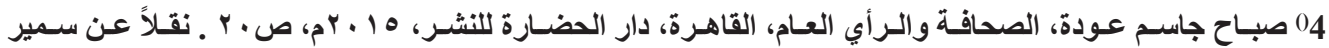

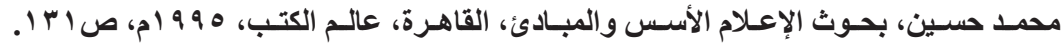

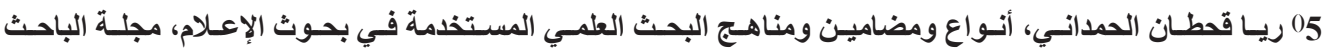

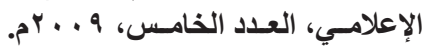

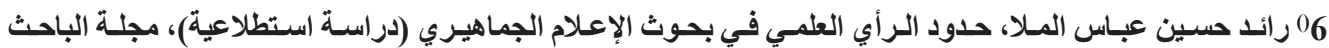

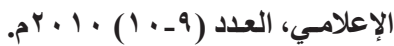

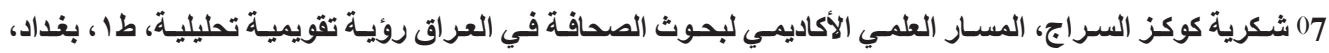

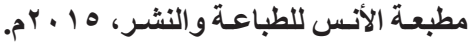

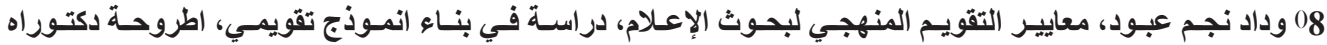

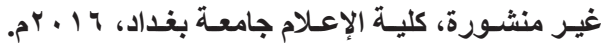

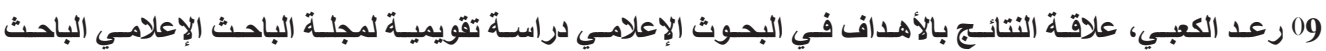

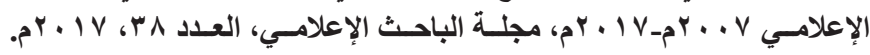

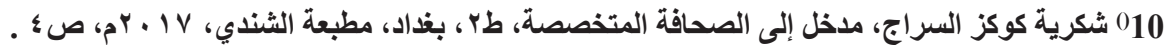

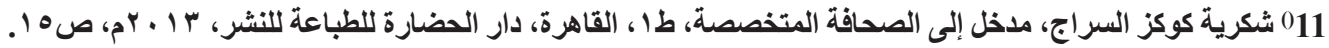

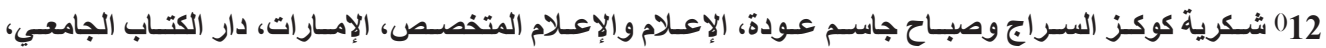

(1)

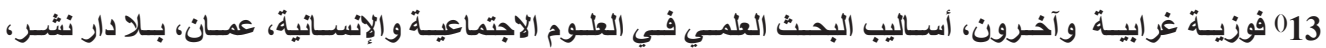

( )

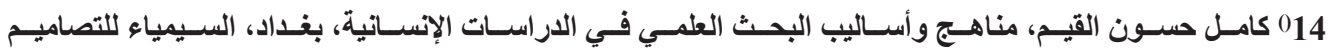

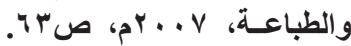

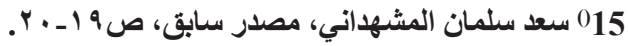
* شمل الحرب النفسية والرأي العام والإعلام البديل.

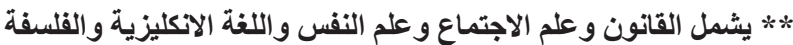

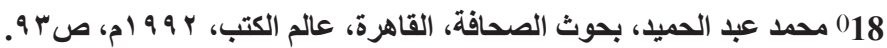

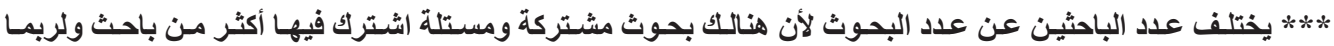
تجـاوز إلى الثلاثـة.

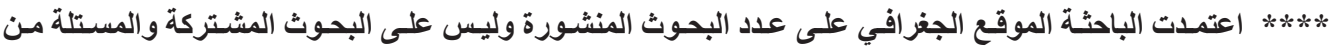

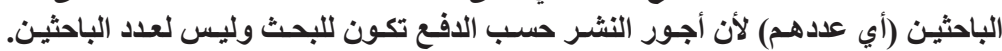

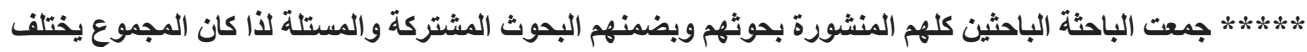

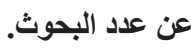

